\title{
Design and Estimation of Multi-Currency Quadratic Models*
}

\author{
MARKUS LEIPPOLD ${ }^{1}$ and LIUREN WU ${ }^{2}$ \\ ${ }^{1}$ Swiss Banking Institute, University of Zurich; ${ }^{2}$ Zicklin School of Business, Baruch College
}

\begin{abstract}
To simultaneously account for the properties of interest-rate term structure and foreign exchange rates within one arbitrage-free framework, we propose a class of multicurrency quadratic models (MCQM) with an $(m+n)$ factor structure in the pricing kernel of each economy. The $m$ factors model the term structure of interest rates. The $n$ factors capture the portion of the exchange rate movement that is independent of the term structure. Our modeling framework represents the first in the literature that not only explicitly allows independent currency movement, but also guarantees internal consistency across all economies without imposing any artificial constraints on the exchange rate dynamics. We estimate a series of multi-currency quadratic models using U.S. and Japanese LIBOR and swap rates and the exchange rate between the two economies. Estimation shows that independent currency factors are essential in releasing the tension between the currency movement and the term structure of interest rates.
\end{abstract}

JEL Classification: G12, G13, E43

\section{Introduction}

The challenge of international term structure modeling is to simultaneously account for the properties of interest-rate term structure and foreign exchange rates within one arbitrage-free framework. Empirical evidence often shows that a predominant portion of exchange rate movement is not related to the interest rate term structure of either economy. Yet, the current literature often models the interest- and exchange rate movements with the same set of

\footnotetext{
* The authors thank Peter Bossaerts (the editor), an anonymous referee, David Backus, Gurdip Bakshi, Rajna Gibson, Michel Habib, Jim Lothian, Tom Urich, and seminar participants at the Georgia Tech conference on international finance, Fordham University, and the University of Zürich for comments. Markus Leippold gratefully acknowledges the financial support of the Swiss National Center of Competence in Research (NCCR) and the University Research Priority Program "Finance and Financial Markets" of the University of Zurich.
} 
state variables, assuming that the exchange rate movement between any two economies is completely controlled by the term structure of interest rates in the two economies. In the few recent studies that allow independent exchange rate movements, either the model introduces internal inconsistency (Brandt and Santa-Clara (2002)), or parametric constraints have to be imposed on the exchange rate dynamics to preclude arbitrage (Han and Hammond (2003)).

In this paper, we propose a class of multi-currency quadratic models (MCQM) with an $(m+n)$ factor structure for the pricing kernel of each economy. Our models represent the first theoretical framework in the literature that not only explicitly allows independent currency movement, but also guarantees internal consistency across all economies without imposing any artificial constraints on the exchange rate dynamics.

Theoretically, we show that the pricing kernel of each economy can have a martingale component composed of factors orthogonal to the pricing of the term structure of interest rates. This martingale component can play important roles in pricing the exchange rate movements between the two economies. In our $(m+n)$ model structure, we use $m$ factors to capture the term structure of interest rates from both economies. We also introduce $n$ factors to capture the independent portion of the currency movement. Our estimation shows that incorporating independent currency factors is essential in releasing the tension between the currency movement and the term structure of interest rates.

To jointly model interest rates and exchange rates, we extend the quadratic term structure models, which combine Gaussian state variables, affine market price of risk, and nonlinear, time-varying conditional variance dynamics into one natural framework. Since the quadratic class uses only Gaussian variables and can easily accommodate an affine market price of risk, the model framework takes full advantage of the flexible Gaussian affine structure (Duffee, 2002 and Dai and Singleton, 2002). Meanwhile, under the quadratic class, bond yields are quadratic functions of the Gaussian variables. Both the instantaneous drift and the instantaneous variances of bond yields are quadratic forms of the Gaussian state variables. Thus, the conditional drift and variance of bond yields accommodate rich nonlinear and time-varying dynamics (Aït-Sahalia (1996a,b)).

We estimate the $(m+n)$ MCQM for the U.S. and Japanese interest rates and the exchange rate between the two economies using $m=3,4,5,6$ term structure factors and $n=1$ independent currency factor. We estimate the models with quasi-maximum likelihood method joint with the unscented Kalman Filter (UKF), a relatively new extended version of the classic Kalman Filter designed to deal with nonlinearities in the measurement equations. The traditional extended Kalman Filter (EKF) approximates the measurement equation by using a linear approximation conditional on the mean forecasts 
on the states. The UKF directly approximates the posterior density by using a set of deterministically chosen sample points (sigma points). This more direct approach is computationally more efficient, since it avoids the calculation of derivatives for the linear approximation. The method also improves the accuracy by reducing the convexity bias induced in the first-order approximation in EKF. This improved efficiency and accuracy enable us to handle the estimation of very large systems. We estimate these large systems on a cross-section of panel data that includes ten years of weekly data on ten U.S. dollar LIBOR and swap rates, ten Japanese Yen LIBOR and swap rates, and the depreciation rates of the dollar price of yen, totaling 21 time series.

Our estimation results highlight the advantage of using our flexible $(m+n)$ model structure. In particular, incorporating the independent currency factor is essential to capturing the exchange rate movement. With this factor, the model can fully accommodate the currency movement at all times. Without it, the model's performance in explaining the exchange rate movement deteriorates dramatically, especially when the number of term structure factors $(n)$ is small.

We find that a $(6+1)$ factor structure statistically dominates models with fewer interest-rate factors. Both preliminary principal component analysis and the estimation results indicate that the interest rates from the two countries share little comovement. Therefore, we need a large number of interest-rate factors to explain the cross-correlations between interest rates at different maturities and in different countries.

We also find a subtle difference between the factor dynamics of U.S. and Japanese interest rates. For the U.S. term structure, the quadratic terms are not significant. Hence, a Gaussian-affine term structure model is sufficient. In contrast, the quadratic terms are significant for the Japanese term structure. We conclude that the Japanese interest rates show more nonlinear dynamics than do their U.S. counterparts.

Researchers have formulated many forecasting relations on interest rates and exchange rates using various forms of expectation hypothesis $(\mathrm{EH})$. In currency forecasting, future currency returns are regressed on the current interestrate differentials between the two economies. Uncovered interest rate parity suggests that the regression slope should be one, yet empirical studies often find negative slope estimates. In interest-rate forecasting, future bond returns are regressed on the current term structure of the interest rates. Empirical evidence again shows that the expectation hypothesis is strongly violated. The estimated $(6+1)$ MCQM can readily accommodate the empirical evidence on both types of forecasting regressions. However, Monte Carlo simulation also shows that these regression slopes often exhibit large sample variations. As a result, out-of-sample forecasting using these $\mathrm{EH}$ regressions is unreliable. We conclude that the real stylized evidence from these regressions is not that the 
slope estimate deviates from the null value under the expectation hypothesis, but that the R-squares of these regressions are always close to zero.

The paper is structured as follows. The next section cites the studies that provide background information on term-structure modeling and currency pricing, and defines the position of our work in the literature. Section 3 lays out the $(m+n)$ multi-currency quadratic model framework that underlies our analysis. Section 4 describes the data set and the estimation methodology. Section 5 discusses the estimation results. Section 6 concludes.

\section{Background}

Earlier works in international term structure modeling include Nielson and Saá-Requejo (1993), Saá-Requejo (1993), Backus, Foresi and Telmar (2001), Dewachter and Maes (2001), Benati (2002), and Hodrick and Vassalou (2002). These papers extend the Cox et al. (1985) model into a multi-factor, international setting.

Yet, the limitations of multi-factor Cox et al. (1985) models have been well documented. For example, Dai and Singleton (2000) and Duffie and Singleton (1997) find that these models have difficulties in explaining the observed correlations between interest rates. Backus, Foresi, Mozumdar and Wu (2001), Duffee (2002), Dai and Singleton (2002), and Roberds and Whiteman (1999) find that the multi-factor Cox et al. (1985) models fail to account for the time-varying risk premium and the results from the $\mathrm{EH}$ regressions on the term structure of interest rates. Backus, Foresi and Telmar (2001) find that the international version of the Cox et al. (1985) model also exhibits strong tensions in simultaneously accounting for the currency regression slopes and the mean term structure of interest rates.

Duffee (2002) shows that, within the affine framework of Duffie and Kan (1996), Gaussian state variables with affine market prices of risk perform much better in accounting for the evidence on bond returns. Dai and Singleton (2002) find that Gaussian variables with affine market prices are also useful in accounting for the evidence on EH regressions. Nevertheless, under a purely Gaussian affine model, continuously compounded interest rates are normally distributed with constant variance. The model cannot accommodate timevarying dynamics in the conditional variance of interest rates. Duffee finds that these Gaussian affine models show the "least ability to fit conditional volatilities".

Quadratic term structure models combine Gaussian state variables, affine market price of risk, and nonlinear, time-varying conditional variance dynamics into one natural framework. Examples of quadratic models 
include Beaglehole and Tenney (1991, 1992), Constantinides (1992), El Karoui et al. (1992), Filipović (2002), Filipović et al. (2004), Gourieroux and Sufana (2003), Jamshidian (1996), Leippold and Wu (2002), Longstaff (1989), and Rogers (1997). Empirical works based on quadratic models include Ahn et al. (2002), Brandt and Chapman (2002), Brandt and Yaron (2001), Leippold and $\mathrm{Wu}$ (2003), and Li and Zhao (2006). These empirical studies conclude that quadratic models outperform affine models in matching both the statistical and economic properties of interest rates. Inci and $\mathrm{Lu}$ (2004) extend the Constantinides (1992) model to currency pricing. Recently, there are also efforts trying to link the affine and quadratic classes into one framework, e.g., Cheng and Scaillet (2002) and Bayraktar et al. (2005).

Many studies forecast currency movements using interest-rate differentials between the two economies, a specification based on the uncovered interest rate parity (UIP). Examples of such studies include Bakshi and Naka (1997), Bekaert (1995), Bekaert et al. (2002), Canova and Marrinan (1995), Engel (1996), Flood and Rose (1996), Flood and Taylor (1996), Froot and Thaler (1990), Hodrick (1987), Phillips and McFarland (1997), and $\mathrm{Wu}$ and Zhang (1997). Most of these studies identify a puzzling tendency for economies with high interest rates to see their currencies appreciate, rather than depreciate as UIP would suggest. The literature labels these deviations from the null hypothesis as the UIP puzzle or the forward premium puzzle. Fama (1984) attributes the forward premium puzzle to certain dynamics of time-varying foreign exchange risk premium and states the necessary conditions to produce this anomaly. Backus, Foresi and Telmer (2001) explain this risk premium within the affine currency pricing framework. Nevertheless, recently Lothian and Wu (2002) use two centuries of historical data to argue that the real puzzle is not the negative regression slope but the low explanatory power of these regressions. They show that the regression slope can become either negative or positive, depending on the sample period, but the R-squares of these regressions are invariably low. This finding indicates that a predominant portion of the exchange rate movement is independent of the interest-rate movements of either economy.

The idea that factors independent of the term structure of interest rates can play an important role in pricing other securities, such as currencies, stocks, and options, dates back to Constantinides (1992), who incorporates an additional state variable in the pricing kernel that does not show up in the term structure. By doing so, he avoids the restrictive assumptions on the stationarity of consumption and price level processes, which are linked to the pricing kernel in equilibrium by the first-order conditions in a representative 
consumer economy. Bansal (1995) and Fisher and Gilles (1999) decompose the pricing kernel into a strictly positive part that prices domestic bonds and a martingale-difference risk component. Since this component does not show up in domestic bond returns, they call it the neutrino factor. Leippold and $\mathrm{Wu}$ (2002) elaborate on the potential roles of these neutrino factors on the pricing of stocks and currencies.

In currency pricing, Brandt and Santa-Clara (2002) expand the affine international term-structure model of Backus, Foresi and Telmer (2001) by augmenting the exchange rate process with a martingale component that is orthogonal to both the domestic and the foreign pricing kernels. Han and Hammond (2003) note that this modeling approach is not internally consistent and violates the fundamental pricing relation. They propose to remove the inconsistency by introducing constraints on the exchange rate dynamics. By comparison, our $(m+n)$ MCQM framework directly incorporates the independent currency movement into the pricing kernel of each economy, rather than superimposing it on the exchange rate without going through the pricing kernel. As such, our modeling framework does not lead to any internal inconsistency, and it does not impose any artificial constraints on the exchange rate dynamics.

\section{The $(m+n)$ Multi-Currency Quadratic Models}

In this section, we propose the $(m+n)$ multi-currency quadratic model framework that simultaneously accounts for the behavior of the term structure of interest rates from different economies, and the exchange rate movements between them.

\subsection{BASIC NOTATION AND ASSUMPTIONS}

We describe the economy by fixing a filtered complete probability space $\left\{\Omega, \mathcal{F}, \mathbb{P},\left(\mathcal{F}_{t}\right)_{0 \leq t \leq \mathcal{T}}\right\}$, with some fixed long horizon $\mathcal{T}$. Our economy consists of $N$ different countries. For convenience, we adopt the view of the U.S. investor as the domestic investor.

We assume no arbitrage in each country. Therefore, for each country, we can identify at least one strictly positive process, $\mathcal{M}_{t}$, which we call the state-price deflator, such that the deflated gains process associated with any admissible trading strategy is a martingale (Duffie, 1992). We further assume that $\mathcal{M}_{t}$ itself is a semimartingale. 
Assumption 1. $\left((m+n)\right.$ Vector of State Variables) Let $Z_{t}=\left[X_{t}, Y_{t}\right]^{\top} \in \mathbb{R}^{m+n}$ be some vector Markov process that describes the state of the economy, with $X_{t} \in \mathbb{R}^{m}, Y_{t} \in \mathbb{R}^{n}$, and $\left\langle X_{t}^{i}, Y_{t}^{j}\right\rangle=0$ for all $i=1,2, \cdots, m$, and $j=1,2, \cdots, n$.

In each country, we assume that there exists a market for default-free bonds at a continuum of maturities $\tau \in[0, \mathcal{T}]$. The time- $t$ price of such a bond is uniquely determined by its maturity and its dependence on the state vector $Z_{t}$. We denote the default-free zero-coupon bond with expiration time $T=t+\tau$ by $P\left(Z_{t}, \tau\right)$. Since $P\left(Z_{t}, 0\right)=1$, no-arbitrage implies

$$
P\left(Z_{t}, \tau\right)=\mathbb{E}_{t}\left[\frac{\mathcal{M}_{T}}{\mathcal{M}_{t}}\right],
$$

where $\mathbb{E}_{t}[\cdot]$ is the expectation operator under the probability measure $\mathbb{P}$ and conditional on the filtration $\mathcal{F}_{t}$. Implicit in the notation for the zero bond is the assumption that the bond price is time homogeneous. In this paper, we confine ourselves to time-homogeneous systems.

Assumption 2. (Orthogonal Decomposition) We express the state-price deflator as

$$
\mathcal{M}_{t}=\xi\left(X_{t}\right) \zeta\left(Y_{t}\right)
$$

where $\xi\left(X_{t}\right)$ and $\zeta\left(Y_{t}\right)$ are some deterministic, twice-differentiable functions in $\mathbb{R}$ such that $\left\langle\xi\left(X_{t}\right), \zeta\left(Y_{t}\right)\right\rangle=0$. Further, the process $\zeta_{t}\left(Y_{t}\right)$ is an exponential martingale under the probability measure $\mathbb{P}$.

To simplify notation, we write $\xi_{t}=\xi\left(X_{t}\right)$ and $\zeta_{t}=\zeta\left(X_{t}\right)$, respectively. Under Assumptions 1 and 2, the martingale component $\zeta_{t}$ does not enter the pricing of zero-coupon bonds:

$$
P\left(Z_{t}, \tau\right)=\mathbb{E}_{t}\left[\frac{\xi_{t+\tau}}{\xi_{t}}\right] \mathbb{E}_{t}\left[\frac{\zeta_{t+\tau}}{\zeta_{t}}\right]=\mathbb{E}_{t}\left[\frac{\xi_{t+\tau}}{\xi_{t}}\right]
$$

In Equation (3), the bond price becomes independent of the state vector $Y_{t}$. Henceforth, we just write $P\left(X_{t}, \tau\right)$ for $P\left(Z_{t}, \tau\right)$. Since the bond price at time $t$ is a function of the state vector $X_{t}$ only, we label $\xi_{t}$ as the term-structure state-price density.

Assumption 3. ([Ornstein-Uhlenbeck Process) The state vectors $X_{t} \in \mathbb{R}^{m}$ and $Y_{t} \in \mathbb{R}^{n}$ are controlled by the following stochastic differential equations:

$$
\begin{gathered}
d X_{t}=-\kappa_{x} X_{t} d t+d W_{t}^{x}, \\
d Y_{t}=-\kappa_{y} Y_{t} d t+d W_{t}^{y},
\end{gathered}
$$


where $W_{t}^{x} \in \mathbb{R}^{m}, W_{t}^{y} \in \mathbb{R}^{n}$ are adapted standard Brownian motions with $\left\langle W^{x}, W^{y}\right\rangle=0$ and $\kappa_{x} \in \mathbb{R}^{m \times m}, \kappa_{y} \in \mathbb{R}^{n \times n}$ control the mean reversions of the two vector processes.

The state vectors $X_{t}$ and $Y_{t}$ follow multivariate Ornstein-Uhlenbeck (OU) processes with mean reversion. For identification purposes, we normalize the two processes to have zero long-run means and identity instantaneous variance. ${ }^{1}$

Under standard no-arbitrage arguments (Duffie, 1992), the term-structure state-price density, $\xi$, must satisfy

$$
\frac{d \xi_{t}}{\xi_{t}}=-r_{t} d t-\gamma_{\xi}\left(X_{t}\right)^{\top} d W_{t}^{x}
$$

where $r_{t}=r\left(X_{t}\right)$ denotes the domestic instantaneous interest rate and the term $\gamma_{\xi}\left(X_{t}\right) \in \mathbb{R}^{m}$ is often referred to as the market price of risk. To differentiate from the risk premium on the state vector $Y_{t}$, we label $\gamma_{\xi}\left(X_{t}\right)$ as the domestic term-structure risk premium, corresponding to the term structure risk factor $X_{t}$.

Next, we introduce the single country quadratic term structure model.

Assumption 4. (Quadratic Term Structure Models) The domestic instantaneous interest rate and term structure risk premiums are given by

$$
\begin{aligned}
r\left(X_{t}\right) & =X_{t}^{\top} A_{r} X_{t}+\mathbf{b}_{r}^{\top} X_{t}+c_{r}, \\
\gamma_{\xi}\left(X_{t}\right) & =A_{\xi} X_{t}+\mathbf{b}_{\xi},
\end{aligned}
$$

where $A_{r}, A_{\xi} \in \mathbb{R}^{m \times m}, \quad \mathbf{b}_{r}, \mathbf{b}_{\xi} \in \mathbb{R}^{m}, c_{r} \in \mathbb{R}$. The same functional forms are assumed for the $N-1$ foreign countries, with parameters given by $\left\{A_{r}^{j}, A_{\xi}^{j}, \mathbf{b}_{r}^{j}, \mathbf{b}_{\xi}^{j}, c_{r}^{j}\right\}, j=2, \ldots, N$.

1 See Leippold and $\mathrm{Wu}$ (2002) for a detailed discussion of the identification issue. For a vector OU process $\widetilde{X}$ with a general affine drift, $(a+b \widetilde{X})$, and general diffusion matrix $\Sigma$, we can always apply the following linear transformation

$$
X=\Sigma^{-1} \widetilde{X}-b^{-1} a,
$$

to normalize the long run mean of $X$ to zero and its diffusion matrix to an identity matrix. Since we later specify the short rate as a quadratic function of $X$ and market prices of risk affine in $X$ (Assumption 4), the short rate is also quadratic in $\widetilde{X}$ and the market prices affine in $\widetilde{X}$. The transformation is only for identification reasons with no loss of generality. The same argument applies to $Y$. 
We write the independent martingale component of the pricing kernel $\zeta\left(Y_{t}\right)$ in the following form,

$$
\frac{d \zeta_{t}}{\zeta_{t}}=-\gamma_{\zeta}\left(Y_{t}\right) d W_{t}^{y}
$$

where $\gamma_{\zeta}\left(Y_{t}\right)$ captures the market risk premium on the innovation $W_{t}^{y}$. Because the state vector $Y_{t}$ and the martingale component $\zeta_{t}$ do not enter the pricing of the term structure, but will determine the exchange rate dynamics between two currencies, we label $Y_{t}$ as the currency risk factor and $\gamma_{\zeta}\left(Y_{t}\right)$ as the currency risk premium. In our empirical application, we also adopt the flexible affine structure for the currency risk premium:

Assumption 5. (Affine Currency Risk Premium) The currency risk premium is affine in the state vector $Y_{t}$,

$$
\gamma_{\zeta}\left(Y_{t}\right)=A_{\zeta} Y_{t}+\mathbf{b}_{\zeta},
$$

where $A_{\zeta} \in \mathbb{R}^{n \times n}, \mathbf{b}_{\zeta} \in \mathbb{R}^{n}$. We also assume the same functional forms for the $N-1$ foreign countries, with parameters given by $\left\{A_{\zeta}^{j}, \mathbf{b}_{\zeta}^{j}\right\}, j=2, \ldots, N$.

In this paper, we use the $(m+n)$ factor structure to separate the termstructure factors from the independent currency risk factors. We can also use an analogous $(m+n)$ decomposition in, for example, stock pricing: The $m$ factors govern the term structure of interest rates and the $n$ factors are orthogonal to the term structure but are correlated with the dynamics of the dividend payments. Then, the $n$ factors do not affect bond pricing, but will affect stock pricing.

\subsection{INTEREST RATES AND FOREIGN EXCHANGE RATES}

Assumptions 3 and 4 identify the quadratic class of term structure models. Under this class, the prices of zero-coupon bonds are exponential-quadratic functions of the Markov process $X_{t}$,

$$
P\left(X_{t}, \tau\right)=\exp \left[-X_{t}^{\top} A(\tau) X_{t}-\mathbf{b}(\tau)^{\top} X_{t}-c(\tau)\right] .
$$


The coefficients $A(\tau) \in \mathbb{R}^{m \times m}, \mathbf{b}(\tau) \in \mathbb{R}^{m}$, and $c(\tau) \in \mathbb{R}$ are solutions to the following ordinary differential equations:

$$
\begin{aligned}
A^{\prime}(\tau) & =A_{r}-A(\tau)\left(\kappa+A_{\gamma}\right)-\left(\kappa+A_{\gamma}\right)^{\top} A(\tau)-2 A(\tau)^{2}, \\
\mathbf{b}^{\prime}(\tau) & =\mathbf{b}_{r}-2 A(\tau) \mathbf{b}_{\gamma}-\left(\kappa+A_{\gamma}\right)^{\top} \mathbf{b}(\tau)-2 A(\tau) \mathbf{b}(\tau), \\
c^{\prime}(\tau) & =c_{r}-\mathbf{b}(\tau)^{\top} \mathbf{b}_{\gamma}+\operatorname{tr}(A(\tau))-\mathbf{b}(\tau)^{\top} \mathbf{b}(\tau) / 2,
\end{aligned}
$$

subject to the boundary conditions $A(0)=0, \mathbf{b}(0)=0$, and $c(0)=0$. There is also an analogous quadratic term structure for foreign countries, with $\{A(\tau), \mathbf{b}(\tau), c(\tau)\}$ replaced by $\left\{A^{j}(\tau), \mathbf{b}^{j}(\tau), c^{j}(\tau)\right\}$. In our empirical application, we use the standard Runge-Kutta method of order four to solve the above ordinary differential equations.

Under no-arbitrage arguments, the dollar price $S_{t}$ of one unit of foreign currency equals the ratio of the foreign state-price deflator to the domestic state-price deflator (Backus, Foresi and Telmer, 2001),

$$
S_{t}^{j}=\frac{\mathcal{M}_{t}^{j}}{\mathcal{M}_{t}} .
$$

Given the orthogonal decomposition in Assumption 2, and the dynamic specifications for the two components in Equations (7) and (10), we obtain the dynamics of the state-price deflator as

$$
\frac{d \mathcal{M}_{t}}{\mathcal{M}_{t}}=\frac{d \xi_{t}}{\xi_{t}}+\frac{d \zeta_{t}}{\zeta_{t}}=-r\left(X_{t}\right) d t+\gamma\left(Z_{t}\right)^{\top} d W_{t}
$$

where $\gamma\left(Z_{t}\right)=\left[\gamma_{\xi}\left(X_{t}\right), \gamma_{\zeta}\left(Y_{t}\right)\right]^{\top}$, and $W_{t}=\left[W_{t}^{x}, W_{t}^{y}\right]^{\top}$, both of which have a dimension of $m+n$. Thus, under Assumptions 4 and 5, we have by Itô's lemma

$$
\begin{aligned}
\frac{d S_{t}^{j}}{S_{t}^{j}}= & \left(r\left(X_{t}\right)-r^{j}\left(X_{t}\right)+\gamma\left(Z_{t}\right)^{\top}\left(\gamma\left(Z_{t}\right)-\gamma^{j}\left(Z_{t}\right)\right)\right) d t \\
& +\left(\gamma\left(Z_{t}\right)-\gamma^{j}\left(Z_{t}\right)\right)^{\top} d W_{t} \\
= & \left(Z_{t}^{\top} A_{\mu}^{j} Z_{t}+\mathbf{b}_{\mu}^{j \top} Z_{t}+c_{\mu}^{j}\right) d t+\left(A_{\sigma}^{j} Z_{t}+\mathbf{b}_{\sigma}^{j}\right)^{\top} d W_{t},
\end{aligned}
$$

with

$$
\begin{aligned}
& A_{\mu}^{j}=\left[\begin{array}{cc}
A_{r}-A_{r}^{j}+A_{\xi}^{\top}\left(A_{\xi}-A_{\xi}^{j}\right) & 0 \\
0^{\top} & A_{\zeta}^{\top}\left(A_{\zeta}-A_{\zeta}^{j}\right)
\end{array}\right], A_{\sigma}^{j}=\left[\begin{array}{cc}
A_{\xi}-A_{\xi}^{j} & 0 \\
0 & A_{\zeta}-A_{\zeta}^{j}
\end{array}\right], \\
& \mathbf{b}_{\mu}^{j}=\left[\mathbf{b}_{r}-\mathbf{b}_{r}^{j}+\mathbf{b}_{\xi}^{\top}\left(2 A_{\xi}-A_{\xi}^{j}\right)-\mathbf{b}_{\xi}^{j \top} A_{\xi}, \mathbf{b}_{\zeta}^{\top}\left(2 A_{\zeta}-A_{\zeta}^{j}\right)-\mathbf{b}_{\zeta}^{j \top} A_{\zeta}\right]^{\top},
\end{aligned}
$$




$$
\begin{aligned}
& \mathbf{b}_{\sigma}^{j}=\left[\mathbf{b}_{\xi}-\mathbf{b}_{\xi}^{j}, \mathbf{b}_{\zeta}-\mathbf{b}_{\zeta}^{j}\right]^{\top}, \\
& c_{\mu}^{j}=c_{r}-c_{r}^{j}+\mathbf{b}_{\xi}^{\top}\left(\mathbf{b}_{\xi}-\mathbf{b}_{\xi}^{j}\right)+\mathbf{b}_{\zeta}^{\top}\left(\mathbf{b}_{\zeta}-\mathbf{b}_{\zeta}^{j}\right) .
\end{aligned}
$$

The exchange rate dynamics in our MCQM framework are characterized by a drift term that is quadratic in the state vector $Z_{t}$, and a diffusion term that is affine in the state vector $Z_{t}$. Furthermore, the $n$ factors $Y_{t}$ do not enter the pricing of interest rates of either country, but they do enter the pricing of the exchange rate between the two countries.

\section{Data and Estimation}

We estimate the international term structure model using ten years of weekly data on U.S. dollar and Japanese yen LIBOR and swap rates, and the exchange rate between the two currencies. The data are weekly (Wednesday) closing mid-quotes from January 2, 1990 to December 31, 1999 (522 observations), provided by Datastream. For each currency, the LIBOR have maturities of one, two, three, six, and 12 months. The swap rates include maturities of two, three, five, seven, and ten years. The exchange rate is represented in dollar prices per unit of Japanese yen. We have a total of 21 interest rate and exchange rate time series.

LIBOR are simply compounded interest rates, related to the continuously compounding spot rates by

$$
\operatorname{LIBOR}\left(X_{t}, \tau\right)=\frac{100}{\tau}\left(e^{\tau Y\left(X_{t}, \tau\right)}-1\right),
$$

where the maturities $\tau$ follow actual-over-360 day-counting convention for both currencies, starting two business days forward. The swap rates for both dollar and yen have payment intervals of six months and are related to the zero-coupon bond prices by

$$
S W A P\left(X_{t}, \tau\right)=200 \times \frac{1-P\left(X_{t}, \tau\right)}{\sum_{i=1}^{2 \tau} P\left(X_{t}, i / 2\right)} .
$$

The day-counting convention for the U.S. dollar swap rates is 30/360 and that for Japanese yen is actual over 365 . 


\subsection{SUMMARY STATISTICS AND PRINCIPAL COMPONENT ANALYSIS}

Table I reports the summary statistics on the LIBOR and swap rates on both U.S. dollar (Panel A) and Japanese yen (Panel B), and also the dollar price of yen (Panel C). The average interest rates for both countries exhibit upwardsloping term structures. The standard deviation of the interest rates decreases with maturity. Both skewness and excess kurtosis are small. All interest rates are highly persistent, with weekly autocorrelations between 0.989 to 0.997 .

We also compute the differentials between interest rates of the same maturities in the two countries and measure their serial correlation. The weekly autocorrelations for the interest-rate differentials range from 0.986 to 0.997. Therefore, we do not observe significant reduction in persistence in the interest-rate differentials between the two countries.

The currency depreciation rates (weekly log returns on dollar price of yen) have a positive sample average of 3.284 in annualized percentages, implying that, on average, the dollar depreciates over yen during the ten-year sample period. The annualized standard deviation of the currency return is $11.67 \%$. In contrast to the high persistence in interest rates and interest rate differentials between the two countries, the currency depreciation rates show little serial dependence. The weekly autocorrelation estimate is only 0.046 .

To obtain a preliminary understanding of the effective dimensionality of the panel data, we perform a principal component analysis (PCA) using the correlation matrix estimates on weekly changes in interest rates and log currency prices. Table II presents the summary results on the marginal and cumulative percentage of variation explained by each principal component. The table shows that we need two principal components to explain over $90 \%$ of the variation in the U.S. dollar interest rates and three principal components to explain over $90 \%$ of the variation in the Japanese yen interest rates. When we pool the two sets of data, we need five principal components to explain the aggregate variation over $90 \%$. Adding the currency depreciation rate necessitates another principal component to explain over $90 \%$ of the variation. Therefore, we do not observe obvious dimension reduction by pooling the data.

We regress each individual series on the mimicking portfolio of each principal component extracted from the 21 series. Table III reports the percentage explained variance for each series by each principal component. We see that the first four principal components explain variations of interest rates in both countries. Nevertheless, we can still identify the major contributing country for each principal component. For example, the first principal explains over $50 \%$ of the variation in the U.S. interest rates. Therefore, we identify this component as the first U.S. interest-rate factor. This factor also explains less 
Table I. Summary statistics of interest rates and exchange rate

The table shows summary statistics of interest rates for both U.S. (Panel A) and Japan (Panel B), and of the weekly log returns on the dollar price of yen (Panel C). Mean, Std. Dev., Skewness, Kurtosis, and Auto denote the sample estimates of the mean, standard deviation, skewness, excess kurtosis, and first-order autocorrelation, respectively. In the maturity column, $\mathrm{m}$ denotes months and y denotes years. The mean and standard deviation of the currency return are in annualized percentages. The data are weekly closing mid quotes from January 2, 1990 to December 31, 1999 (522 observations), provided by Datastream.

\begin{tabular}{rccccr}
\hline Maturity & Mean & Std. Dev. & Skewness & Kurtosis & Auto \\
\hline \multicolumn{5}{c}{ Panel A: LIBOR and Swap Rates on U.S. Dollars } \\
\hline $1 \mathrm{~m}$ & 5.353 & 1.376 & 0.347 & 0.106 & 0.989 \\
$2 \mathrm{~m}$ & 5.405 & 1.364 & 0.345 & 0.106 & 0.992 \\
$3 \mathrm{~m}$ & 5.445 & 1.354 & 0.327 & 0.089 & 0.992 \\
$6 \mathrm{~m}$ & 5.548 & 1.337 & 0.316 & 0.067 & 0.993 \\
$12 \mathrm{~m}$ & 5.772 & 1.324 & 0.331 & 0.013 & 0.991 \\
$2 \mathrm{y}$ & 6.124 & 1.275 & 0.514 & -0.002 & 0.990 \\
$3 \mathrm{y}$ & 6.400 & 1.218 & 0.638 & -0.065 & 0.989 \\
$5 \mathrm{y}$ & 6.770 & 1.163 & 0.716 & -0.239 & 0.990 \\
$7 \mathrm{y}$ & 6.992 & 1.148 & 0.694 & -0.374 & 0.990 \\
$10 \mathrm{y}$ & 7.199 & 1.116 & 0.639 & -0.467 & 0.990 \\
\hline & & Panel B: LIBOR and Swap Rates on Japanese Yen & & \\
\hline & & & & \\
$1 \mathrm{~m}$ & 2.825 & 2.750 & 0.835 & -0.743 & 0.997 \\
$2 \mathrm{~m}$ & 2.821 & 2.743 & 0.856 & -0.706 & 0.997 \\
$3 \mathrm{~m}$ & 2.811 & 2.732 & 0.874 & -0.671 & 0.997 \\
$6 \mathrm{~m}$ & 2.801 & 2.693 & 0.893 & -0.618 & 0.996 \\
$12 \mathrm{~m}$ & 2.834 & 2.637 & 0.890 & -0.575 & 0.996 \\
$2 \mathrm{y}$ & 3.026 & 2.500 & 0.769 & -0.733 & 0.996 \\
$3 \mathrm{y}$ & 3.286 & 2.384 & 0.640 & -0.892 & 0.996 \\
$5 \mathrm{y}$ & 3.719 & 2.161 & 0.452 & -1.064 & 0.996 \\
$7 \mathrm{y}$ & 4.006 & 1.967 & 0.323 & -1.126 & 0.996 \\
$10 \mathrm{y}$ & 4.230 & 1.801 & 0.307 & -1.099 & 0.996 \\
\hline
\end{tabular}

Panel C: Weekly Returns on Dollar Price of 100 Yen

\begin{tabular}{llllll}
\hline- & 3.284 & 11.67 & 0.650 & 3.424 & 0.046 \\
\hline
\end{tabular}

than $30 \%$ of the variation in the Japanese interest rates, a sign of comovements between the interest rates in the two countries.

The second principal component explains $35.41 \%$ of variation in the Japanese interest rates, and $19.32 \%$ of variation in the U.S. interest rates, so we regard it as the first Japanese interest-rate factor. A similar comparison leads us to classify the third principal component as the second Japanese interest-rate factor and the fourth principal component as the second U.S. interest-rate factor. 
Table II. PCA for U.S. and Japanese interest rates and exchange rate

We perform principal component analysis (PCA) on the panel data of U.S. and Japanese interest rates and the exchange rate between the two countries. Entries report the percentage variation explained by each of the first 10 principal components. We compute the percentage based on the relative magnitude of the eigenvalues of the covariance matrix of weekly changes on interest rates and $\log$ currency prices. Panel A reports the marginal explained variance. Panel B reports the cumulative percentage. The four columns within each panel represent four portfolios of data. Under USD are U.S. dollar interest rates (ten series), under JPY are Japanese yen interest rates (ten series), under UJR are interest rates from both countries (20 series), and under UJC are the whole panel of interest rates and exchange rate (21 series). The data are weekly from January 2, 1990 to December 31, 1999 (522 observations for each time series).

\begin{tabular}{|c|c|c|c|c|c|c|c|c|}
\hline \multirow[b]{2}{*}{ PC } & \multicolumn{4}{|c|}{ Panel A: Marginal } & \multicolumn{4}{|c|}{ Panel B: Cumulative } \\
\hline & USD & JPY & UJR & UJF & USD & JPY & UJR & UJF \\
\hline 1 & 71.48 & 64.12 & 40.59 & 38.72 & 71.48 & 64.12 & 40.59 & 38.72 \\
\hline 2 & 19.42 & 20.56 & 27.36 & 26.06 & 90.90 & 84.69 & 67.95 & 64.78 \\
\hline 3 & 4.19 & 7.11 & 11.33 & 10.80 & 95.09 & 91.80 & 79.28 & 75.58 \\
\hline 4 & 2.08 & 2.97 & 8.65 & 8.30 & 97.17 & 94.77 & 87.93 & 83.87 \\
\hline 5 & 1.17 & 2.53 & 3.66 & 4.69 & 98.34 & 97.30 & 91.59 & 88.57 \\
\hline 6 & 0.83 & 1.23 & 2.11 & 3.45 & 99.17 & 98.53 & 93.71 & 92.01 \\
\hline 7 & 0.38 & 0.60 & 1.49 & 2.01 & 99.56 & 99.13 & 95.19 & 94.03 \\
\hline 8 & 0.32 & 0.46 & 1.35 & 1.41 & 99.88 & 99.58 & 96.55 & 95.44 \\
\hline 9 & 0.07 & 0.24 & 0.87 & 1.28 & 99.95 & 99.83 & 97.41 & 96.72 \\
\hline 10 & 0.05 & 0.17 & 0.65 & 0.83 & 100.00 & 100.00 & 98.06 & 97.55 \\
\hline
\end{tabular}

The first four principal components contribute little to the exchange rate movement. In contrast, the fifth principal component explains $92.99 \%$ of the variation of the currency depreciation rate, indicating that this component is mainly responsible for currency movement. This principal component contributes almost nothing to the interest-rate movements of either country. This result supports our claim that exchange rate movements are mostly independent of the interest-rate movement of the two countries.

The sixth and seventh factors contribute marginally to the short-term Japanese and U.S. interest rates, respectively. We classify them as the third interest-rate factor of each country.

Table IV measures the correlation of the mimicking portfolio of each principal component with each individual series. The first factor is highly (negatively) correlated with the U.S. interest rates, more so for moderate maturity swap rates. For example, its correlation with the two-year swap rate is -0.81 . This principal component also shows a highly negative correlation with the two-year Japanese swap rates, generating positive comovement between the levels of the two countries' interest rates. The second principal component is strongly and 
Table III. Variance decomposition on U.S. and Japanese interest rates and exchange rate

We perform PCA on the panel data of weekly changes in the U.S. and Japanese LIBOR, swap rates, and the log dollar price of yen (21 series). Entries report the percentage variation explained by each principal component on each individual series. We base our calculations on marginal regressions. Data are weekly from January 2, 1990 to December 31, 1999 (522 observations for each time series).

\begin{tabular}{|c|c|c|c|c|c|c|c|c|}
\hline \multicolumn{2}{|c|}{ Factors } & 1 & 2 & 3 & 4 & 5 & 6 & 7 \\
\hline \multirow[t]{11}{*}{ U.S. } & $1 \mathrm{~m}$ & 24.80 & 6.17 & 27.44 & 15.69 & 0.01 & 2.78 & 19.49 \\
\hline & $2 \mathrm{~m}$ & 36.12 & 14.26 & 20.63 & 15.83 & 0.39 & 0.01 & 0.25 \\
\hline & $3 \mathrm{~m}$ & 43.85 & 17.99 & 13.82 & 15.71 & 0.41 & 0.52 & 0.95 \\
\hline & $6 \mathrm{~m}$ & 54.72 & 22.62 & 5.24 & 8.01 & 0.44 & 0.87 & 3.57 \\
\hline & $12 \mathrm{~m}$ & 60.29 & 25.26 & 0.56 & 1.16 & 0.02 & 0.68 & 3.29 \\
\hline & $2 y$ & 65.09 & 24.30 & 1.83 & 3.39 & 0.10 & 0.00 & 0.10 \\
\hline & $3 y$ & 64.29 & 23.62 & 3.08 & 6.46 & 0.10 & 0.01 & 0.01 \\
\hline & $5 y$ & 60.32 & 21.28 & 5.28 & 11.09 & 0.03 & 0.07 & 0.36 \\
\hline & $7 y$ & 57.91 & 19.56 & 6.52 & 12.67 & 0.00 & 0.15 & 0.74 \\
\hline & $10 \mathrm{y}$ & 53.47 & 18.14 & 8.01 & 13.51 & 0.01 & 0.29 & 1.19 \\
\hline & egated & 52.09 & 19.32 & 9.24 & 10.35 & 0.15 & 0.54 & 3.00 \\
\hline \multirow[t]{10}{*}{ Japan } & $1 \mathrm{~m}$ & 12.63 & 22.21 & 28.76 & 8.28 & 1.57 & 15.25 & 1.17 \\
\hline & $2 \mathrm{~m}$ & 16.69 & 31.70 & 23.33 & 12.64 & 0.56 & 4.31 & 3.19 \\
\hline & $3 \mathrm{~m}$ & 21.97 & 36.82 & 16.79 & 9.17 & 0.44 & 0.35 & 4.39 \\
\hline & $9 \mathrm{~m}$ & 22.02 & 39.01 & 9.80 & 6.49 & 0.59 & 16.72 & 0.86 \\
\hline & $12 \mathrm{~m}$ & 25.49 & 42.12 & 2.39 & 2.34 & 0.81 & 22.13 & 1.69 \\
\hline & $2 y$ & 39.80 & 41.59 & 4.60 & 2.79 & 0.01 & 0.21 & 0.08 \\
\hline & $3 y$ & 41.24 & 39.66 & 7.22 & 4.21 & 0.11 & 0.01 & 0.31 \\
\hline & $5 y$ & 40.83 & 38.45 & 10.39 & 5.24 & 0.06 & 0.94 & 0.03 \\
\hline & $7 y$ & 35.64 & 33.05 & 15.28 & 8.17 & 0.04 & 2.00 & 0.24 \\
\hline & $10 \mathrm{y}$ & 33.98 & 29.49 & 15.86 & 8.59 & 0.01 & 2.68 & 0.31 \\
\hline \multicolumn{2}{|c|}{ Japan aggregated } & 29.03 & 35.41 & 13.44 & 6.79 & 0.42 & 6.46 & 1.23 \\
\hline \multicolumn{2}{|c|}{ Exchange Rate } & 1.51 & 0.07 & 0.13 & 2.76 & 92.99 & 2.40 & 0.02 \\
\hline \multicolumn{2}{|l|}{ Total } & 38.70 & 26.06 & 10.81 & 8.30 & 4.70 & 3.45 & 2.01 \\
\hline
\end{tabular}

negatively correlated with the Japanese interest rates, but positively correlated with the U.S. interest rates. This sign difference in correlation may in part negate the positive comovements generated from the first principal component.

The third and fourth principal components have an obvious slope structure. The third factor is positively correlated with the short-term rates from both countries, but negatively correlated with the long-term rates from both countries, generating a positive slope on the term structure of both countries. The fourth principal component, on the other hand, generates a positive slope on the U.S. term structure, but a negative slope on the Japanese term structure.

The first and third principal components contribute similarly to the interest rates in both countries, generating positive comovement. However, the second and fourth principal components contribute in opposite directions to the term 
Table IV. Correlations of the mimicking PCA portfolios with U.S. and Japanese interest rates and exchange rates

We perform PCA on the panel data of U.S. and Japanese LIBOR and swap rates, in weekly differences, and weekly depreciation rates of the dollar price of Japanese yen (21 series). Entries report the correlations between the mimicking portfolios of each of the principal components and each individual interest-rate and depreciation-rate time series. Data are weekly from January 2, 1990 to December 31, 1999 (522 observations for each time series).

\begin{tabular}{|c|c|c|c|c|c|c|c|c|}
\hline \multicolumn{2}{|c|}{ Factors } & 1 & 2 & 3 & 4 & 5 & 6 & 7 \\
\hline \multirow[t]{11}{*}{ U.S. } & $1 \mathrm{~m}$ & -0.50 & 0.25 & 0.52 & 0.40 & 0.01 & 0.17 & 0.44 \\
\hline & $2 \mathrm{~m}$ & -0.60 & 0.38 & 0.45 & 0.40 & 0.06 & -0.01 & -0.05 \\
\hline & $3 \mathrm{~m}$ & -0.66 & 0.42 & 0.37 & 0.40 & 0.06 & -0.07 & -0.10 \\
\hline & $6 \mathrm{~m}$ & -0.74 & 0.48 & 0.23 & 0.28 & 0.07 & -0.09 & -0.19 \\
\hline & $12 \mathrm{~m}$ & -0.78 & 0.50 & 0.08 & 0.11 & 0.01 & -0.08 & -0.18 \\
\hline & $2 y$ & -0.81 & 0.49 & -0.14 & -0.18 & -0.03 & -0.00 & -0.03 \\
\hline & $3 y$ & -0.80 & 0.49 & -0.18 & -0.25 & -0.03 & 0.01 & 0.01 \\
\hline & $5 y$ & -0.78 & 0.46 & -0.23 & -0.33 & -0.02 & 0.03 & 0.06 \\
\hline & $7 y$ & -0.76 & 0.44 & -0.26 & -0.36 & -0.00 & 0.04 & 0.09 \\
\hline & $10 y$ & -0.73 & 0.43 & -0.28 & -0.37 & 0.01 & 0.05 & 0.11 \\
\hline & egated & -0.72 & 0.43 & 0.06 & 0.01 & 0.01 & 0.00 & 0.02 \\
\hline \multirow[t]{10}{*}{ Japan } & $1 \mathrm{~m}$ & -0.36 & -0.47 & 0.54 & -0.29 & -0.13 & 0.39 & 0.11 \\
\hline & $2 \mathrm{~m}$ & -0.41 & -0.56 & 0.48 & -0.36 & -0.07 & 0.21 & -0.18 \\
\hline & $3 \mathrm{~m}$ & -0.47 & -0.61 & 0.41 & -0.30 & -0.07 & 0.06 & -0.21 \\
\hline & $9 \mathrm{~m}$ & -0.47 & -0.62 & 0.31 & -0.25 & 0.08 & -0.41 & 0.09 \\
\hline & $12 \mathrm{~m}$ & -0.50 & -0.65 & 0.15 & -0.15 & 0.09 & -0.47 & 0.13 \\
\hline & $2 y$ & -0.63 & -0.64 & -0.21 & 0.17 & 0.01 & -0.05 & 0.03 \\
\hline & $3 y$ & -0.64 & -0.63 & -0.27 & 0.21 & 0.03 & -0.01 & 0.06 \\
\hline & $5 y$ & -0.64 & -0.62 & -0.32 & 0.23 & 0.02 & 0.10 & 0.02 \\
\hline & $7 y$ & -0.60 & -0.57 & -0.39 & 0.29 & 0.02 & 0.14 & -0.05 \\
\hline & $10 \mathrm{y}$ & -0.58 & -0.54 & -0.40 & 0.29 & 0.01 & 0.16 & -0.06 \\
\hline \multicolumn{2}{|c|}{ Japan aggregated } & -0.53 & -0.59 & 0.03 & -0.02 & -0.00 & 0.01 & -0.01 \\
\hline \multicolumn{2}{|c|}{ Exchange Rate } & 0.12 & -0.03 & 0.04 & -0.17 & 0.96 & 0.15 & -0.01 \\
\hline \multicolumn{2}{|l|}{ Total } & -0.59 & -0.08 & 0.04 & -0.01 & 0.05 & 0.01 & 0.00 \\
\hline
\end{tabular}

structure of the interest rates in the two countries. Therefore, they generate negative comovements between the interest rates of the two countries. These two opposing forces result in low average cross-correlation between the interest-rate movements in the two countries.

The first four principal components are almost completely independent of the currency movement, but the fifth principal component has an almost perfect correlation with the exchange rate movements and near zero correlations with any interest-rate series. Again, we see that the exchange rate moves quite independently of the interest rates of the two countries.

The principal component analysis provides us with a general idea on the factor structure of the interest rates and exchange rate. We can summarize each 
country's interest rate movements with a maximum of three factors. Interest rates in the two countries share some comovements, but not enough to reduce the dimensionality of the system. We also find that the exchange rate movement shares little comovement with the interest rates from either country. Based on this data analysis, we estimate a series of $(m+n)$ multi-currency quadratic models with the number of interest-rate factors between three to six and with one independent currency factor. That is, $m=3,4,5,6$ and $n=1$. To gauge the statistical significance of the independent currency factor, we also estimate a series of models without the currency factors, i.e., $m=3,4,5,6$ and $n=0$.

\subsection{QUASI MAXIMUM LIKELIHOOD ESTIMATION WITH UNSCENTED KALMAN FILTER}

We cast the estimation problem into a state-space form and estimate the models using a quasi maximum likelihood method joint with an unscented Kalman Filter (UKF). The unscented Kalman Filter is an extension of the classic Kalman Filter to deal with nonlinear systems. (See the Appendix for technical details of this methodology.)

The state-space representation consists of a pair of state propagation equations and measurement equations. In our estimation, the dynamics of the state vectors $Z_{t}=\left[X_{t}, Y_{t}\right]^{\top}$ control the state propagation equation, which we can write in discrete time format as,

$$
Z_{t}=\Phi Z_{t-\Delta}+\sqrt{Q} \varepsilon_{t},
$$

where $\varepsilon \sim I I N(0, I), \Phi=\exp (-\kappa \Delta)$ with $\Delta$ being the discrete time interval, and

$$
\kappa=\left[\begin{array}{cc}
\kappa_{x} & 0 \\
0 & \kappa_{y}
\end{array}\right]
$$

denotes the mean-reverting matrix of the stacked state vector. The conditional variance matrix $Q$ can be written as

$$
Q=\int_{0}^{\Delta} e^{-s \kappa} e^{-s \kappa^{\top}} d s
$$

the value of which can be represented as functions of eigenvalues and eigenvectors of $\kappa$. Since we use weekly data, $\Delta=1 / 52$.

We construct the measurement equations using the observed LIBOR and swap rates, and also the depreciation rates of the dollar price of Japanese yen, 
assuming additive normal observation errors,

$$
y_{t}=\left[\begin{array}{c}
\operatorname{LIBOR}\left(X_{t}, i\right)^{U S} \\
\operatorname{LIBOR}(X, i)^{J P} \\
\operatorname{SWAP}\left(X_{t}, i\right)^{U S} \\
\operatorname{SWAP}\left(X_{t}, i\right)^{J P} \\
\Delta s^{J P}\left(Z_{t}\right)
\end{array}\right]+e_{t}, \quad \operatorname{cov}\left(e_{t}\right)=R, \quad \begin{aligned}
& i=1,2,3,6,12 \text { months } \\
& i=1,2,3,6,12 \text { months } \\
& i=2,3,5,7,10 \text { years } \\
& i=2,7,10 \text { years }
\end{aligned}
$$

where $\Delta s^{j}\left(Z_{t}\right)=\ln \left(S_{t}^{j} / S_{t-\Delta}\right)$ denotes the model-implied log-depreciation rate for the dollar price of Japanese yen. From Equation (15) and Itô's lemma, we Euler-approximate the log-depreciation rates as,

$$
\begin{aligned}
& s_{t}^{j}\left(Z_{t}\right) \\
& =\left(Z_{t-\Delta}^{\top} A_{\mu}^{j} Z_{t-\Delta}+\mathbf{b}_{\mu}^{j \top} Z_{t-\Delta}+c_{\mu}^{j}-\frac{1}{2}\left(A_{\sigma}^{j} Z_{t-\Delta}+\mathbf{b}_{\sigma}^{j}\right)^{\top}\left(A_{\sigma}^{j} Z_{t-\Delta}+\mathbf{b}_{\sigma}^{j}\right)\right) \Delta \\
& \quad+\left(A_{\sigma}^{j} Z_{t-\Delta}+\mathbf{b}_{\sigma}^{j}\right)^{\top} \varepsilon\left(Z_{t}\right)
\end{aligned}
$$

where $\varepsilon\left(Z_{t}\right)=Z_{t}-\Phi Z_{t-\Delta}$ denotes the exchange rate innovation inferred from the state vectors of the Euler-approximated diffusion dynamics.

For our estimation, we assume that the measurement errors on each series are independent but with distinct variance $\sigma^{2}$. We also confine the mean-reversion matrices $\kappa, A_{\gamma}, A_{\gamma}^{j}$ to be lower triangular. Thus, with a $3+1$ factor structure (three term structure factors and one currency factor), we have 70 parameters to be estimated on 21 time series: $\Theta=\left[\sigma \in \mathbb{R}^{21+}, \kappa \in \mathbb{R}^{7}, A_{r} \in \mathbb{R}^{6+}, A_{r}^{j} \in \mathbb{R}^{6+}, b_{r} \in \mathbb{R}^{3+}, b_{r}^{j} \in \mathbb{R}^{3+}\right.$, $c_{r} \in \mathbb{R}, c_{r}^{j} \in \mathbb{R}, A_{\xi} \in \mathbb{R}^{6}, A_{\xi}^{j} \in \mathbb{R}^{6}, b_{\xi} \in \mathbb{R}^{3}, b_{\xi}^{j} \in \mathbb{R}^{3}, A_{\zeta} \in \mathbb{R}, A_{\zeta}^{j} \in \mathbb{R}, b_{\zeta} \in \mathbb{R}$, $\left.b_{\zeta}^{j} \in \mathbb{R}\right]$. Analogously, the $4+1$ factor model involves 94 parameters; the $5+1$ factor model involves 123 parameters, and the $6+1$ factor model, 157 parameters. The corresponding models without the independent currency factor $(n=0)$ have five less parameters than their $n=1$ counterparts. These five parameters are $\left[\kappa_{y}, A_{\zeta}, A_{\zeta}^{j}, b_{\zeta}, b_{\zeta}^{j}\right]$. We are capable of estimating such a large system because of the stability of the algorithm. 


\section{Estimation Results}

Given the estimation results, we analyze the performance of MCQMs with different number of factors. Based on the estimates on the best-performing model, we analyze the factor and interest rate dynamics.

\subsection{MODEL PERFORMANCE}

In Panel $\mathrm{A}$ of Table $\mathrm{V}$, we report the log likelihood value estimate for each MCQM. Panel B constructs a likelihood ratio test between the most general $(6+1)$ model and all the other models. The likelihood ratio statistic, $\mathcal{L} \mathcal{R}$, is twice the difference between the log likelihood values of the two relevant models. Asymptotically, this statistic has a chi-square distribution with the degree of freedom equal to the number of constraints. We compute the degree of freedom as the sum of the number of the extra model parameters and the number of observations for each extra state variable. Since the sample length is 522, each extra state variable generates 522 extra degrees of freedom.

Visually inspecting the log likelihood value estimates in Panel A of Table V, we find that the MCQM with the $(6+1)$ factor structure generates the highest likelihood. The likelihood ratio tests in Panel B show that the superior performance of the $(6+1)$ factor structure over all other models are strongly statistically significant. For comparison, we report the $99 \%$ critical values for each test in the last row. The likelihood statistics are all much higher than their corresponding $99 \%$ critical values. Therefore, the $(6+1)$ model statistically dominates all the other models with fewer interest-rate or exchange rate factors.

The statistical significance of the superiority of the $(6+1)$ factor structure over the $(6+0)$ factor structure illustrates the importance of the independent currency factor. On the other hand, the statistical significance of $(6+1)$ over $(m+1)$, with $m=3,4,5$, shows that we need six interest-rate factors to capture the interest-rate movements in the two countries.

For single-country term-structure modeling, a three-factor structure has become a norm. Pure statistical analysis also confirms that three factors explain the majority of the variation in interest rates. ${ }^{2}$ Both our estimation results and the principal component analysis indicate that pooling the data of interest rates and exchange rates from the two countries does not reduce the dimensionality of the system. We still require three factors to explain the interest rate behavior in each country, and one factor to explain the independent variation of the exchange rate. When estimating a multi-currency

\footnotetext{
${ }^{2}$ See, for example, Dai and Singleton (2000, 2003), Duffee (1996, 2002), Heidari and Wu (2003), Knez et al. (1994), Litterman and Scheinkman (1991), and Steeley (1990).
} 


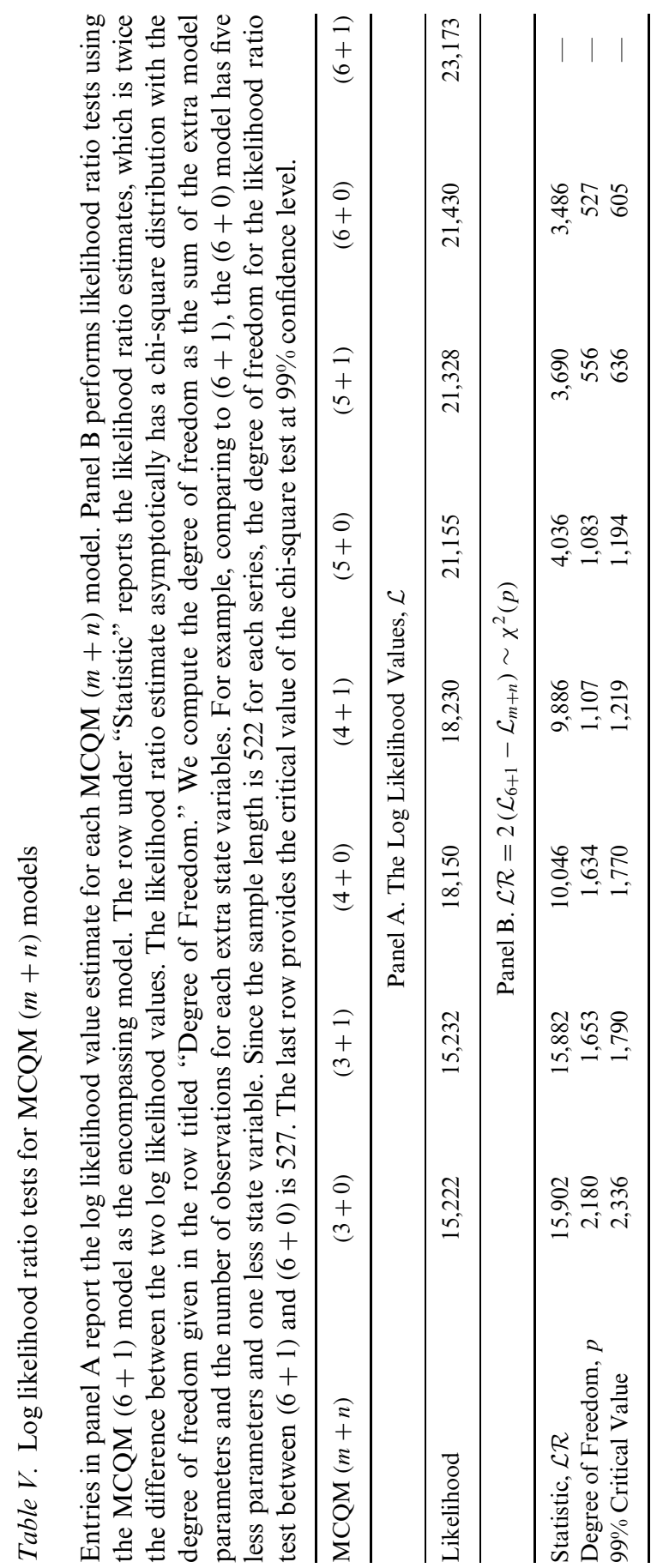


quadratic model with the pooled data of interest rates and exchange rates, we need the sum of all these factors.

\subsection{FACTOR DYNAMICS AND FACTOR LOADING}

Table VI summarizes the parameter estimates on the factor dynamics under both the objective and the risk-neutral measures in the $(6+1)$ MCQM. $^{3}$ In the parentheses after each parameter estimate, we report the absolute magnitude of the $t$-statistics computed using the BHHH estimator (Hamilton, 1994).

Under MCQM, both the interest-rate and currency factors follow OrnsteinUhlenbeck processes. Such processes are stationary when the real part of the eigenvalues of the $\kappa$ matrix is positive. In estimation, we constrain $\kappa$ to be lower triangular. The eigenvalues of the lower-triangular matrix coincide with the diagonal elements of the matrix, which we constrain to be positive to maintain the stationarity of the system.

From the estimates on $\kappa_{x}$, we observe that the time-series dynamics for the interest rates are highly persistent. The first three eigenvalues of $\kappa_{x}$ (the first three diagonal terms) cannot be distinguished from zero. ${ }^{4}$ The estimates for most of the elements in $\kappa_{x}$ have small $t$-values, showing the inherent difficulty in identifying the time series dynamics of interest rates. This difficulty represents a generic issue for estimating the interest rate dynamics and is a result of the near unit root behavior of interest rates. (See Duffee (2002) and Duffee and Stanton (2005) for more detailed discussions.)

On the other hand, we can estimate the risk-neutral counterparts $\kappa_{x, U S}^{*}=$ $\kappa_{x}+A_{\xi}^{U S}$ and $\kappa_{x, J P}^{*}=\kappa_{x}+A_{\xi}^{J P}$ with much better accuracy, as evidenced by the larger $t$ values. These risk-neutral dynamics control the term-structure behavior of interest rates. Thus, although it is difficult to estimate the timeseries dynamics of interest rates, the MCQM can accurately determine the cross-sectional properties (term structure) of interest rates.

The constant parts of the market price of risk $b_{\xi}^{U S}$ and $b_{\xi}^{J P}$ contribute to a constant drift term in the risk-neutral factor dynamics. Most elements are estimated with statistical significance. The one factor, $Y$, that controls the exchange rate depreciation shows strong mean reversion under both the objective and the risk-neutral measure. However, the estimates also show large standard errors, so the $t$-values are relatively small.

The parameters reported in Table VII control the loading of the $(6+1)$ factors on the interest rates and the exchange rate. The matrix $A_{r}^{j}, j=U S, J P$

\footnotetext{
3 The parameter estimates on MCQM models with $m=3,4,5$ and $n=0,1$ are available upon request.

4 The estimate for the fifth diagonal element of the $\kappa_{x}$ matrix is abnormally large, potentially due to the transitory nature of higher-order dynamics and/or the effect of measurement errors.
} 
Table VI. Factor dynamics under the $(6+1)$ MCQM

Entries report the estimates of the parameters in the $(6+1)$ MCQM that control the objective and risk-neutral dynamics of the interest rate and exchange rate factors. The absolute magnitude of the $t$-statistics computed using the BHHH estimator are reported in parentheses. We estimate the model using quasi maximum likelihood method joint with UKF. The data consists of weekly observations on (1) LIBOR at maturities of one, two, three, six, and 12 months and (2) swap rates at maturities of two, three, five, seven, and ten years for both U.S. dollars and Japanese yen. The data are closing mid-quotes from January 2, 1990 to December 31, 1999 (522 observations).

\begin{tabular}{|c|c|c|c|c|c|c|c|}
\hline$\kappa_{x}=$ & $\begin{array}{r}0.000(0.00) \\
0.029(0.15) \\
0.080(0.40) \\
0.189(0.35) \\
2.812(1.11) \\
-0.308(0.46)\end{array}$ & $\begin{array}{r}0 \\
0.000(0.00) \\
-0.178(1.21) \\
0.447(2.03) \\
-6.388(1.93) \\
0.354(0.49)\end{array}$ & $\begin{array}{r}0 \\
0 \\
0.000(0.00) \\
0.059(0.08) \\
-15.71(3.68) \\
-0.531(0.30)\end{array}$ & $\begin{array}{r}0 \\
0 \\
0 \\
0.642(1.37) \\
25.78(4.53) \\
-0.748(0.32)\end{array}$ & $\begin{array}{r}0 \\
0 \\
0 \\
0 \\
63.34(18.9) \\
-3.584(0.66)\end{array}$ & $\begin{array}{r}0 \\
0 \\
0 \\
0 \\
0 \\
1.517(1.76)\end{array}$ & , \\
\hline$\kappa_{x, U S}^{*}=$ & $\begin{array}{r}0.026(1.42) \\
0.152(1.13) \\
-0.526(3.38) \\
0.113(1.22) \\
-0.102(1.46) \\
-0.177(1.86)\end{array}$ & $\begin{array}{rr}0 & 0 \\
& -0.390(5.24) \\
-0.063(1.44) \\
-0.046(0.72) \\
-0.043(0.33)\end{array}$ & $\begin{array}{r}0 \\
0 \\
1.188(12.9) \\
-0.007(0.05) \\
0.084(1.20) \\
0.386(1.98)\end{array}$ & $\begin{array}{rr} \\
0.116(4.59) \\
0.182(3.75) \\
-0.117(1.23)\end{array}$ & $\begin{array}{rr}0 & \\
0 & \\
0 & \\
) & \\
) & 0.576(18.2 \\
) & -0.276(1.12\end{array}$ & $\begin{array}{ll}0 & \\
0 & \\
0 & \\
0 & \\
2) & \\
\text { 2) } & 0.056(3.37\end{array}$ & $\begin{array}{l}0 \\
0 \\
0 \\
0 \\
0 \\
7)\end{array}$ \\
\hline
\end{tabular}

\begin{aligned} \hline$b_{\xi}^{U S}=\left[\begin{array}{rrrrrrr}0.221(0.91) & 21.14(7.28) & 6.910(1.34) & -5.701(2.19) & 6.221(3.68) & 4.741(1.49)\end{array}\right]^{\top} \\ , \kappa_{x, J P}^{*}=\left[\begin{array}{rrrrrr}0.035(1.80) & 0 & 0 & 0 & 0 & 0 \\ 0.142(1.06) & 0.396(5.30) & 0 & 0 & 0 & 0 \\ -0.500(3.34) & -0.330(1.51) & 1.138(13.0) & 0 & 0 & 0 \\ 0.085(0.97) & -0.116(2.04) & 0.010(0.07) & 0.068(3.22) & 0 & 0 \\ -0.245(3.00) & -0.105(0.96) & 0.334(4.30) & -0.026(0.96) & 0.282(8.07) & 0 \\ -0.148(1.59) & -0.071(0.65) & 0.252(1.31) & 0.003(0.04) & 0.011(0.05) & 0.073(3.34)\end{array}\right]\end{aligned}$,

$b_{\xi}^{J P}=\left[\begin{array}{llllll}0.240(0.96) & 21.18(7.30) & 6.934(1.34) & -5.905(2.25) & 5.959(3.64) & 4.720(1.48)\end{array}\right]^{\top}$,

$\kappa_{y}=16.56(0.75), \kappa_{y, U S}^{*}=27.59(1.24), \kappa_{y, J P}^{*}=27.60(1.24), b_{\zeta}^{U S}=5.323(1.77), b_{\zeta}^{J P}=5.815(1.72)$.

captures the nonlinear (quadratic) impact of the six factors on the U.S. and Japanese interest rates, respectively. The vector $b_{r}^{j}, j=U S, J P$ captures the factors' linear impact on interest rates.

For the U.S. interest rates, we find that the nonlinear impacts of the factors are very small. The estimates for most of the elements in $A_{r}^{U S}$ are close to zero, and none of the elements has a $t$-value greater than 1.96 , the critical value for $95 \%$ confidence level. These insignificant estimates suggest that the interest-rate loadings of the factors are mostly linear in the United States. Therefore, a Gaussian-affine model does a good job of capturing the U.S. dollar interest-rate movements. Our findings for the U.S. term structure are in 
line with the results in previous single-country empirical studies on quadratic models such as, e.g., Ahn et al. (2002), Brandt and Chapman (2002), Brandt and Yaron (2001), Leippold and Wu (2003), and Li and Zhao (2006).

The linear impact of the factors on the U.S. interest rates is captured by $b_{r}^{U S}$. The last three elements of $b_{r}^{U S}$ are not distinguishable from zero. Thus, the U.S. interest rates are mainly controlled by the first three interest-rate factors with mostly linear loadings.

The story for the Japanese interest rates is quite different. The quadratic loadings of the first three interest-rate factors remain close to zero. Hence, we can conclude that the first three factors are linear-Gaussian factors. However, the quadratic loadings of the last three factors on the Japanese interest rates are strongly significant. Thus, although the U.S. interest rates can be modeled by Gaussian-affine models, the quadratic terms play important roles in the Japanese interest rates.

Table VII. Factor loadings under the $(6+1)$ MCQM

Entries report the estimates of the parameters in the $(6+1)$ MCQM that control the loading of the factors on the interest rates. The absolute magnitude of the $t$-statistics computed using the $\mathrm{BHHH}$ estimator are reported in parentheses. We estimate the model using quasi maximum likelihood method joint with UKF. The data consists of weekly observations on (1) LIBOR at maturities of one, two, three, six, and 12 months and (2) swap rates at maturities of two, three, five, seven, and ten years for both U.S. dollars and Japanese yen. The data are closing mid-quotes from January 2, 1990 to December 31, 1999 (522 observations).

$\sqrt{A_{r}^{U S}}=\left[\begin{array}{cccccc}0.000(0.00) & 0 & 0 & 0 & 0 & 0 \\ 0.000(0.00) & 0.000(0.00) & 0 & 0 & 0 & 0 \\ -0.003(0.01) & -0.000(0.00) & -0.010(0.01) & 0 & 0 & 0 \\ 0.001(0.00) & 0.000(0.00) & 0.002(0.00) & 0.000(0.00) & 0 & 0 \\ -0.005(0.35) & -0.021(1.16) & -0.046(1.71) & 0.115(1.94) & 0.256(1.83) & 0 \\ -0.004(0.28) & -0.015(0.63) & -0.032(0.96) & 0.082(1.05) & 0.184(0.95) & 0.012(1.17)\end{array}\right]$,

\begin{tabular}{l}
\hline$b_{r}^{U S}=\left[\begin{array}{llllll}0.001(1.39) & 0.006(7.65) & 0.003(1.49) & 0.000(0.00) & 0.000(0.00) & 0.000(0.00)\end{array}\right]^{\top}$, \\
$c_{r}^{U S}=0.084(3.74)$,
\end{tabular}

$\sqrt{A_{r}^{J P}}=\left[\begin{array}{rrrrrr}-0.000(0.00) & 0 & 0 & 0 & 0 & 0 \\ -0.000(0.00) & -0.000(0.00) & 0 & 0 & 0 & 0 \\ -0.007(0.31) & -0.004(0.46) & 0.019(0.84) & 0 & 0 & 0 \\ -0.007(0.75) & -0.002(0.26) & 0.019(1.43) & -0.025(5.30) & 0 & 0 \\ 0.017(1.76) & -0.016(1.22) & -0.060(4.50) & 0.054(3.20) & 0.166(5.40) & 0 \\ -0.001(0.12) & 0.034(3.24) & 0.023(1.33) & -0.052(2.53) & -0.220(8.18) & 0.030(6.70)\end{array}\right]$,

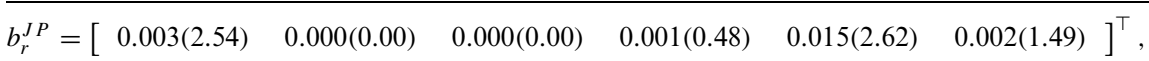

$c_{r}^{J P}=0.067(2.43)$. 
This finding contrasts to some extent the findings of Nowman (2001), who concludes from his study that a two-factor Vasicek (1977) model provides the best fit for Japanese interest rates. ${ }^{5}$ However, Nowman only compares the models of Chan et al. (1992) and Cox et al. (1985) to the Vasicek model. In addition, the data used in Nowman (2001) consist only of short-term interest rates, i.e., one-month and twelve-months rates from 1981 to 1999. In another related study on the expectation hypothesis, Ruge-Murcia (2006) argues that zero lower bounds for the term structure induce a convex relation between short and long-term interest rates. For countries in which the implications of a zero lower bound may be empirically relevant, he finds that nonlinear models deliver smaller forecasting errors than linear models. Our results for Japan support Ruge-Murcia's argument.

Finally, the linear loading $b_{r}^{J P}$ indicates that the last three factors are mostly for the Japanese interest rates. The first factor also has a linear contribution to the Japanese interest rates, thus generating some comovement between the two countries' interest rates. The second and third factors have little impact on the Japanese interest rates, either linearly or nonlinearly.

\subsection{CROSS-CORRELATIONS OF INTRA-AND INTER-COUNTRY INTEREST RATES}

Table VIII reports the cross-correlation matrix between the weekly changes in interest rates in the United States and Japan. We find that changes of interest rates at different maturities within the same country show relatively strong correlation, but the correlation is much smaller for interest rates from different countries. The cross-correlations among interest rates within a single country average at 0.68 for the U.S. and 0.6 for Japan. In contrast, the cross-correlations between rates from different countries average 0.16 . Within the same country, the correlation between two interest rates declines as the maturity gap between the two rates increases.

Most term structure models of a single economy imply cross-correlations between interest rates that are much higher than observed. To see how the MCQM performs in capturing the comovements of interest rates, we simulate 1,000 sample paths of interest rates and depreciation rates with the parameter estimates for the $(6+1)$ MCQM. Each sample path has 522 weeks, the same as the actual data sample. We then measure the cross-correlation of the modelimplied interest rates from the 1,000 simulated sample paths. Table IX reports the sample mean and standard deviation of the cross-correlation estimates obtained from the 1,000 simulated samples.

5 Other studies on the Japanese term structure include Tse (1995), Shoji and Ozaki (1996), and Nowman (1999). 
Table VIII. Cross-correlation between interest rates moves

Entries are the cross-correlation estimates between weekly changes in U.S. and Japanese interest rates at selected maturities (one, six, and 12-month LIBORs, and two, five, and 10-year swaps). The data are weekly closing mid-quotes from January 2, 1990 to December 31, 1999 (522 observations), downloaded from Datastream.

\begin{tabular}{|c|c|c|c|c|c|c|c|c|c|c|}
\hline & \multicolumn{5}{|c|}{ US } & \multicolumn{5}{|c|}{ Japan } \\
\hline & $1 \mathrm{~m}$ & $1 \mathrm{y}$ & $2 y$ & $5 y$ & $10 \mathrm{y}$ & $1 \mathrm{~m}$ & $1 \mathrm{y}$ & $2 \mathrm{y}$ & $5 y$ & $10 \mathrm{y}$ \\
\hline $1 \mathrm{~m}$ & 1.00 & 0.50 & 0.38 & 0.30 & 0.26 & 0.30 & 0.11 & 0.12 & 0.11 & 0.08 \\
\hline $1 y$ & 0.50 & 1.00 & 0.87 & 0.77 & 0.71 & 0.12 & 0.14 & 0.20 & 0.20 & 0.19 \\
\hline $2 y$ & 0.38 & 0.87 & 1.00 & 0.95 & 0.88 & 0.12 & 0.15 & 0.24 & 0.24 & 0.23 \\
\hline $5 y$ & 0.30 & 0.77 & 0.95 & 1.00 & 0.96 & 0.11 & 0.16 & 0.24 & 0.26 & 0.24 \\
\hline $10 \mathrm{y}$ & 0.26 & 0.71 & 0.88 & 0.96 & 1.00 & 0.08 & 0.14 & 0.24 & 0.27 & 0.26 \\
\hline $1 \mathrm{~m}$ & 0.30 & 0.12 & 0.12 & 0.11 & 0.08 & 1.00 & 0.45 & 0.37 & 0.35 & 0.26 \\
\hline $1 y$ & 0.11 & 0.14 & 0.15 & 0.16 & 0.14 & 0.45 & 1.00 & 0.68 & 0.59 & 0.49 \\
\hline $2 y$ & 0.12 & 0.20 & 0.24 & 0.24 & 0.24 & 0.37 & 0.68 & 1.00 & 0.90 & 0.79 \\
\hline $5 y$ & 0.11 & 0.20 & 0.24 & 0.26 & 0.27 & 0.35 & 0.59 & 0.90 & 1.00 & 0.91 \\
\hline $10 y$ & 0.08 & 0.19 & 0.23 & 0.24 & 0.26 & 0.26 & 0.49 & 0.79 & 0.91 & 1.00 \\
\hline
\end{tabular}

On average, the model generates intra-country interest-rate correlations that are higher than the sample estimate, but inter-country correlations that are lower than the sample estimate. The average intra-currency interest-rate correlation implied from the simulation (standard error in parentheses) is 0.73 (0.24) for the U.S. and $0.86(0.12)$ for Japan, as compared to the estimates of 0.68 and 0.6 from the actual data. The differences between the observed and model-implied intra-currency cross-correlations are not statistically significant. On the other hand, the inter-currency average correlation is $-0.31(0.2)$, significantly lower than the sample estimate of 0.16 from the actual data. Thus, the $(6+1)$ model can generate intra-currency interest-rate comovements that are not significantly different from the sample estimates, but the implied inter-currency interest-rate correlation is lower than observed.

To compare the performance of different MCQMs, we also perform the same Monte Carlo simulation for the $(3+1)$ model. Table $\mathrm{X}$ reports the mean and standard deviation of the correlation estimates. The correlations between intra-currency interest rates generated from the $(3+1)$ model are much higher than observed in the data. The average value and standard error is $0.9(0.09)$ for the U.S. interest rates and $0.99(0.01)$ for the Japanese interest rates, significantly higher than the sample estimates of 0.68 and 0.6 . On other hand, the inter-currency average correlation is $0.01(0.02)$, which remains significantly lower than the sample estimate of 0.16 . The low standard errors of these simulated values also indicate that the $(3+1)$ model becomes quite 


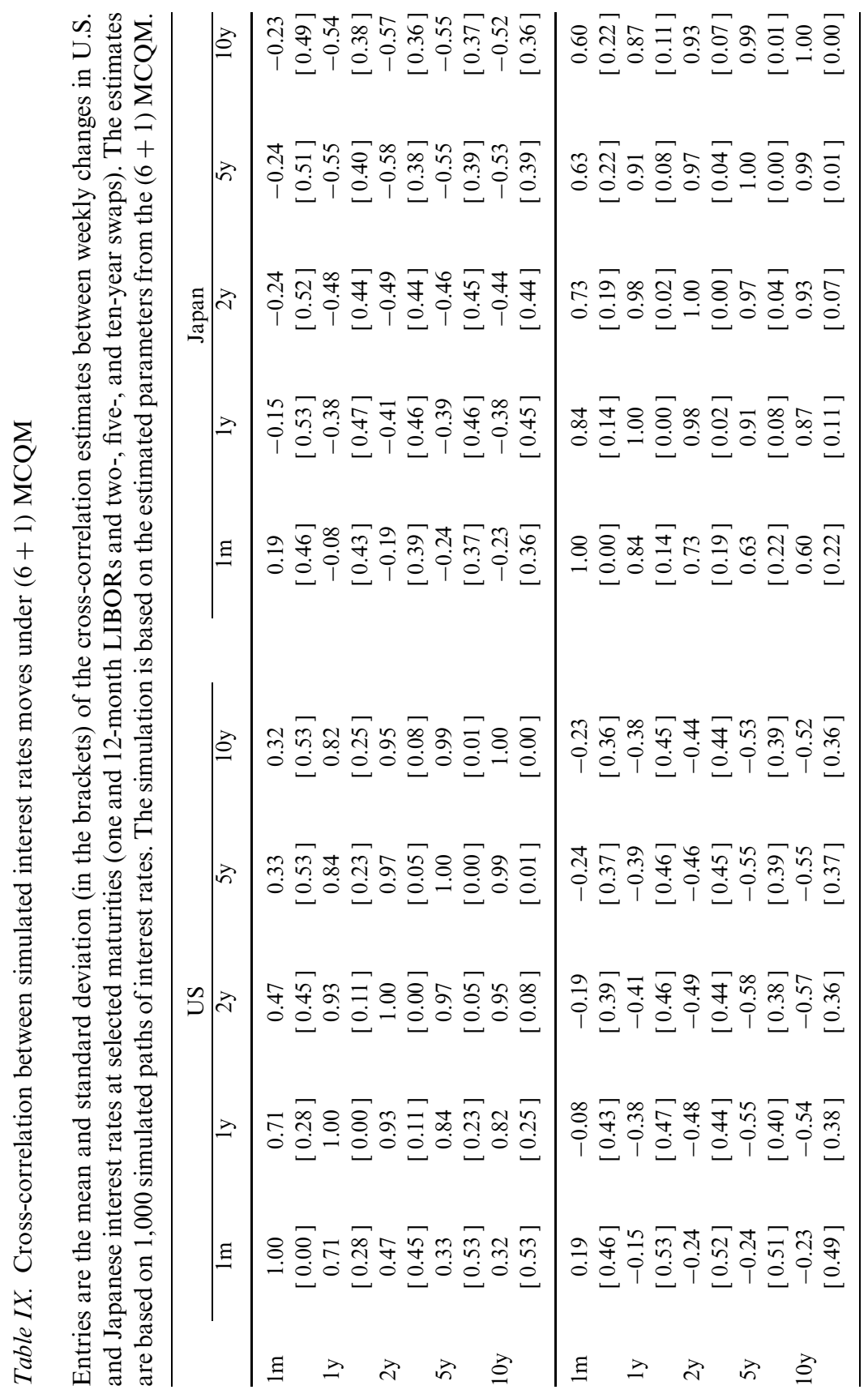




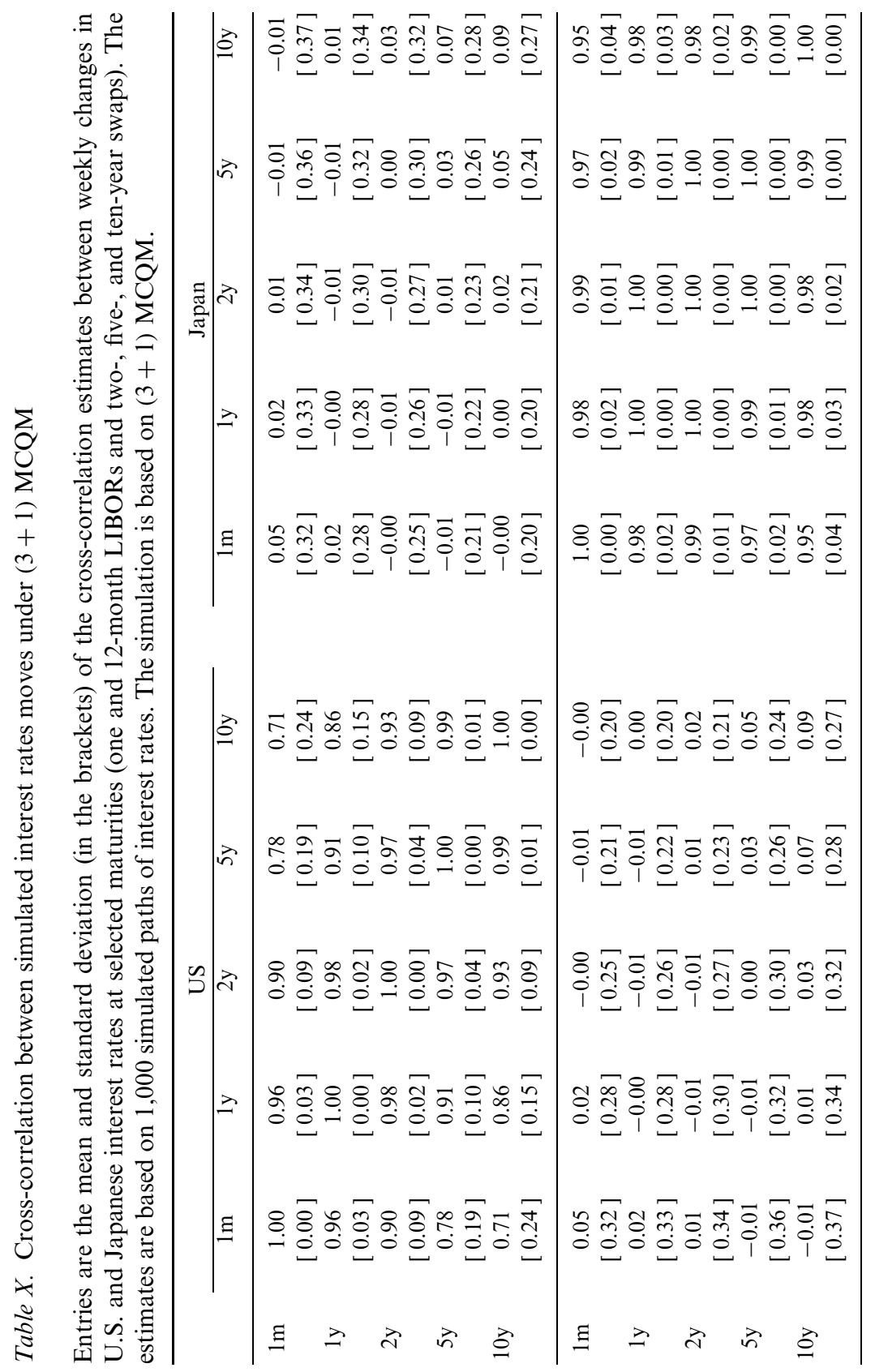


rigid and therefore has difficulty in capturing the observed features of interest rates. This evidence points to the necessity for a high number of interest-rate factors, such as $(6+1)$.

\subsection{INDEPENDENT CURRENCY MOVEMENT}

To assess the influence of the independent currency factor, Table XI reports two statistics. In the row titled " $R^{2}$," we report the explained variation of the exchange rate depreciation rate, defined as one minus the ratio of the pricing error variance to the variance of the weekly depreciation rates, similar to the $\mathrm{R}$-squared definition. The pricing error is defined as the difference between the model-implied and the observed weekly depreciate rate. The statistics show that with $m \leq 5$ and without an independent currency risk factor $(n=0)$, the MCQMs fail to explain the variation in currency movements. The explained variations of the depreciation rates are all negative, suggesting that a basic random walk assumption explains the depreciation rate better than the specific MCQM model. Only when we include six interest rate factors, can we explain the currency movement reasonably well without the independent currency factor. In contrast, when we introduce one independent currency risk factor $n=1$, we can fit the currency movements to near perfection regardless of the number of interest rate factors.

In the row titled "Ratio", we calculate the ratio of the standard deviation of the model-implied currency depreciation rates to that of the observed depreciate rates. Without an independent currency risk factor $(n=0)$, the ratio is less than one for $m=3,4$, and 5. In contrast, with one independent currency risk factor, the standard deviation of the model-implied exchange rate becomes almost identical to that of the historical rate. This finding is in line with that in Brandt amd Santa-Clara (2002) and Han and Hammond (2003) for the U.S. and UK term structures. These authors augment the three interest rate factor model in Backus, Foresi and Telmer (2001) with an additional currency factor and show that the three interest rate factors alone cannot generate enough variation for the log currency return.

Table XII reports the correlation estimates between the weekly depreciation rate and interest rates of different maturities, for both model-implied values and historical data. For each estimated model, we extract the model-implied exchange rates and interest rates using the unscented Kalman filter and compute the correlation on the extracted series. The last column reports the estimates from the historical data for comparison. Again, the benefit of incorporating the independent currency risk factor is obvious, especially when the number of interest rate factors is small. For example, the $(3+0)$ 
Table XI. Explaining the variation in exchange rates

Entries under the row titled " $R^{2}$ " report the explained variation for the weekly exchange rate depreciation rates, defined as one minus the ratio of the pricing error variance to the variance of the weekly currency returns. Entries under the row titled "Ratio" report the ratio of standard deviations of the model-implied and the historical exchange rate.

\begin{tabular}{lrcrrrrrr}
\hline Models & $(3+0)$ & $(3+1)$ & $(4+0)$ & $(4+1)$ & $(5+0)$ & $(5+1)$ & $(6+0)$ & $(6+1)$ \\
\hline$R^{2}$ & -0.04 & 1.00 & -0.36 & 1.00 & -0.46 & 1.00 & 1.00 & 1.00 \\
Ratio & 0.27 & 1.00 & 0.71 & 1.00 & 0.80 & 1.00 & 1.00 & 1.00 \\
\hline
\end{tabular}

model even fails to match the historical signs of the correlation coefficients. In contrast, the $(3+1)$ specification generates a near perfect fit for the sign and a reasonable fit for the magnitude of the correlation coefficients. The $(6+1)$

Table XII. Cross-correlation between currency depreciation rates and interest rate changes

Entries are the cross-correlation estimates between weekly changes in the exchange rate and U.S. and Japanese interest rates at different maturities. The exchange rates and interest rates are extracted from the estimated models using the unscented Kalman filter. The last column reports the correlation estimates from the historical data. The last row reports the average correlation estimate difference between the model-implied data and the historical data.

\begin{tabular}{lrrrrrr}
\hline Models & & $(3+0)$ & $(3+1)$ & $(6+0)$ & $(6+1)$ & hist. \\
\hline U.S. & $1 \mathrm{~m}$ & 0.057 & -0.027 & -0.034 & -0.032 & -0.037 \\
& $2 \mathrm{~m}$ & 0.057 & -0.027 & -0.034 & -0.033 & -0.038 \\
& $3 \mathrm{~m}$ & 0.058 & -0.027 & -0.033 & -0.034 & -0.035 \\
& $6 \mathrm{~m}$ & 0.057 & -0.026 & -0.032 & -0.035 & -0.029 \\
& $12 \mathrm{~m}$ & 0.054 & -0.023 & -0.029 & -0.033 & -0.029 \\
& $2 \mathrm{y}$ & 0.045 & -0.017 & -0.021 & -0.024 & -0.022 \\
& $3 \mathrm{y}$ & 0.033 & -0.010 & -0.012 & -0.013 & -0.014 \\
& $5 \mathrm{y}$ & 0.016 & 0.000 & 0.002 & 0.003 & 0.002 \\
& $7 \mathrm{y}$ & 0.006 & 0.005 & 0.011 & 0.012 & 0.012 \\
\hline \multirow{2}{*}{ Japan } & $10 \mathrm{y}$ & -0.001 & 0.008 & 0.018 & 0.020 & 0.021 \\
& $1 \mathrm{~m}$ & -0.054 & 0.035 & 0.034 & 0.034 & 0.031 \\
& $2 \mathrm{~m}$ & -0.054 & 0.035 & 0.035 & 0.035 & 0.032 \\
$3 \mathrm{~m}$ & -0.054 & 0.034 & 0.036 & 0.035 & 0.034 \\
& $9 \mathrm{~m}$ & -0.053 & 0.033 & 0.039 & 0.036 & 0.037 \\
& $12 \mathrm{~m}$ & -0.052 & 0.032 & 0.041 & 0.038 & 0.038 \\
$2 \mathrm{y}$ & -0.054 & 0.031 & 0.041 & 0.040 & 0.038 \\
& $3 \mathrm{y}$ & -0.056 & 0.031 & 0.040 & 0.039 & 0.038 \\
& $5 \mathrm{y}$ & -0.059 & 0.032 & 0.038 & 0.037 & 0.036 \\
& $7 \mathrm{y}$ & -0.061 & 0.032 & 0.037 & 0.034 & 0.033 \\
& $10 \mathrm{y}$ & -0.061 & 0.032 & 0.037 & 0.032 & 0.031 \\
\hline
\end{tabular}


model also generates better correlation estimates on average than the $(6+0)$ model, although to a lesser degree. Overall, the independent currency risk factor is crucial to explaining the exchange rate movement and its correlation with interest rates.

\subsection{THE FORWARD PREMIUM REGRESSION}

Currency forecasting is often formulated in terms of the uncovered interest rate parity regression:

$$
s_{t+\Delta}-s_{t}=\alpha+\beta\left(y_{t}-y_{t}^{j}\right)+e_{t+\Delta},
$$

where $y_{t}$ denotes the time- $t$ value of the spot rate with maturity $\Delta$. Given the almost perfect fitting of the $(6+1)$ model on both interest rates and the exchange rate, we can use this estimated model as a smoothing base to extract the spot rate and forward rate curves. Doing so avoids the internal inconsistencies of using the traditional smoothing functions such as the NelsonSiegel family (Filipović, 1999). Given the extracted spot rates and the observed exchange rate, ${ }^{6}$ we run the forward premium regression and obtain the following results:

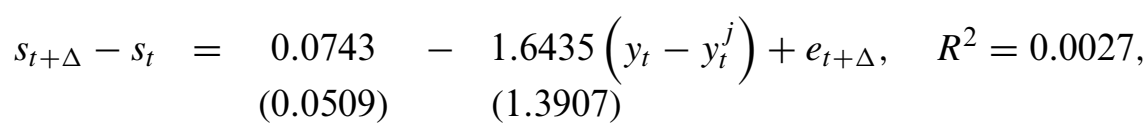

where $y_{t}$ and $y_{t}^{j}$ denotes the one-week spot rates on U.S. dollar and Japanese yen, respectively. The standard errors of the estimates are in the parentheses below the estimates.

First, the slope estimate is strongly negative, far away from the null hypothesis of one. If true, this result implies that the high-interest-rate currency also tends to appreciate. Therefore, it is profitable to always invest in the highinterest-rate currency. Similar evidence has been repeatedly surveyed in the literature.

Nevertheless, the negative slope estimate is qualified by two additional observations. First, the standard errors of the intercept and slope estimates are very large, which makes the estimates less reliable. Second, the R-square of the regression is very small at 0.0027 . Thus, the forecasting power of this regression is minimal. Always investing in the high-interest-rate currency becomes a very

6 The extracted and observed exchange rates are the same under our $(6+1)$ model, because the model can fit the exchange rate perfectly ex post. 


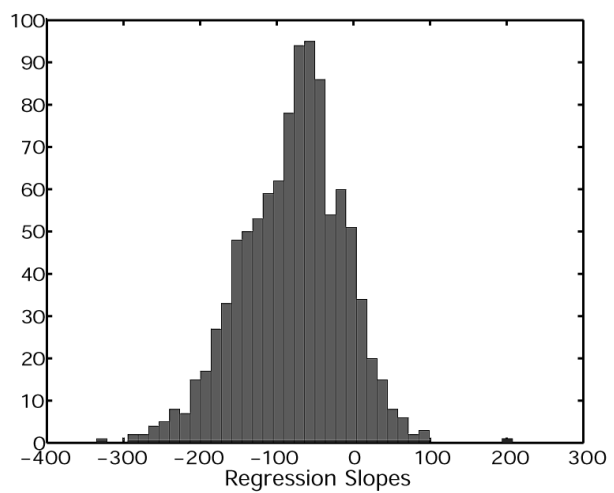

Figure 1. Forward-premium regression slopes based on simulated paths. We estimate the regression slopes using 1,000 simulated paths of interest rates and exchange rates. The simulation is performed under the $(6+1)$ MCQM and the parameter estimates in Tables VI and VII.

risky strategy because the interest rate differential has little to say about the currency movement, despite the large negative slope estimate.

The MCQM framework allows flexible specifications for the risk premium and so in principle can easily explain the negative regression slope estimates. To verify this, we run the regressions in (23) based on the 1,000 simulated sample paths generated in Section 5.3 for the $(6+1)$ MCQM. With the parameters estimated from the $(6+1)$ model, we simulate 1,000 paths of the state vectors, each with a length of 522, the same length as our data sample. Then, we compute the implied spot rates and exchange rates, based on the simulated state vectors and the model parameter estimates. For each simulated path, we run the regression in Equation (23) and store the slope estimates. Figure 1 depicts the histogram of the slope estimates from the 1,000 simulated paths.

The histogram shows that the slope estimate can be as negative as -300 or as positive as 200 . This wide dispersion indicates that the $(6+1)$ model can accommodate almost any estimates from this regression, but it also shows that, because of the extremely high sample dependence, a negative regression slope is not that puzzling.

\subsection{EXPECTATION HYPOTHESES ON INTEREST RATES}

The MCQM framework can be applied not only for currency pricing, but also for the pricing of the term structure of interest rates in the two countries. Similar to the forward premium regression, many studies have formulated forecasting regressions on interest rates, based on different forms of the expectation hypothesis. Backus, Foresi, Mozumdar and Wu (2001) propose a 

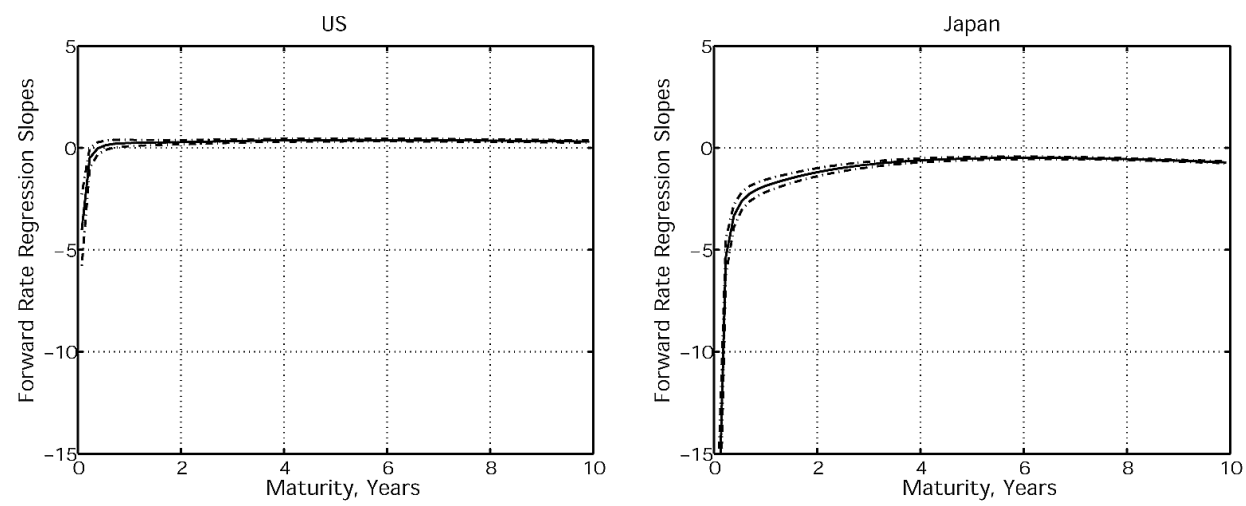

Figure 2. Forward-rate regressions. The solid lines denote the regression slope estimates of the following regression

$$
f_{t+1}^{n}-r_{t}=a_{n}+b_{n}\left(f_{t}^{n}-r_{t}\right)+e_{t+1}
$$

where $f_{t}^{n}$ denotes time- $t$ forward rates between time $t+n$ and $t+n+\Delta$, and $r$ is the short rate. The dashed dotted lines are the $95 \%$ confidence interval constructed based on the standard deviation estimates of the regression slopes. We extract the forward rates from the data obtained by the $(6+1)$ model. The R-square averages about $8 \%$ for the U.S. regressions and $38 \%$ for Japan.

regression equation under the martingale hypothesis on the forward rate:

$$
f_{t+\Delta}^{h-\Delta}-r_{t}=a_{h}+b_{h}\left(f_{t}^{h}-r_{t}\right)+e_{t+\Delta}^{h},
$$

where $f_{t}^{h}$ is the time- $t$ forward rate between $t+h$ and $t+(h+\Delta)$. Expectation hypothesis says that the regression slope should be one, but most slope estimates for this regression are below one, particularly at short maturities.

Given the extracted forward rates in the U.S. and Japan, we run the regression in (25) at different maturities. Figure 2 plots the regression slopes as a function of the maturity of the forward rates. The forward-rate regression slope estimates on the U.S. interest rates are similar to those reported in Backus, Foresi, Mozumdar and Wu (2001) for the U.S. Treasury data. The slope estimates at short maturities have the largest deviation from the null value of one, but as maturity increases, the slope estimates come closer to the null value of one.

The forward-rate regressions on the Japanese data are different. Again, the largest deviation from the null hypothesis is at the short maturities. But as maturity increases, the regression slope stays below zero. Overall, the deviation from the null hypothesis is larger for the Japanese interest rates than for the U.S. interest rates. 

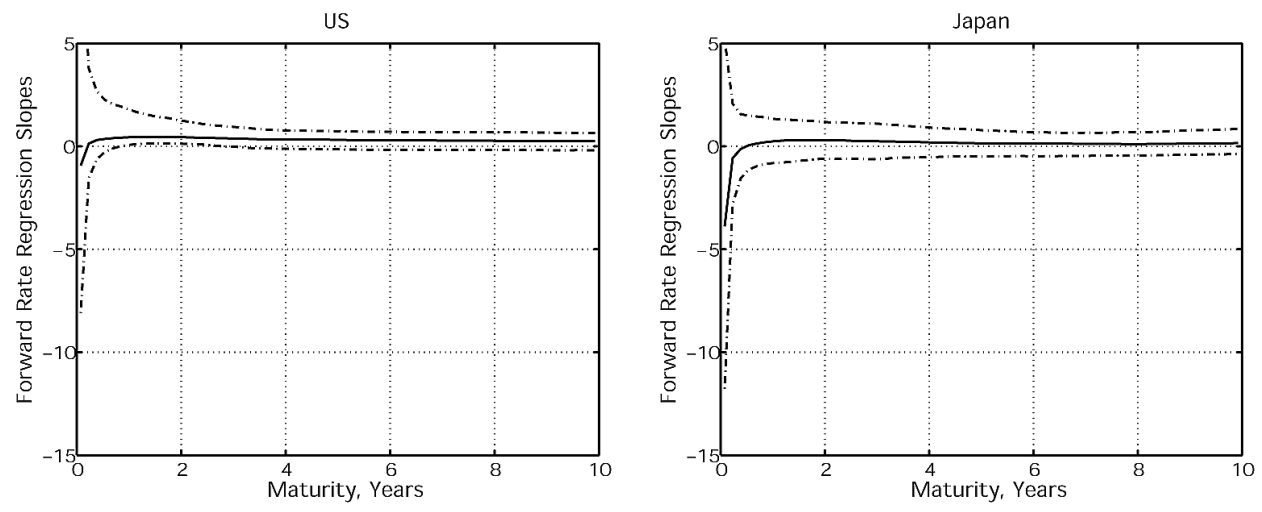

Figure 3. Forward rate regressions based on simulated sample paths. Lines denote the median (solid line) and 5\% and 95\% percentiles of the forward rate regression based on 1,000 simulated paths of forward rates. Each path has an weekly frequency and 300 observations. We simulate the paths for the $(6+1)$ MCQM with parameter estimates in Tables VI and VII.

Since Gaussian-affine models are degenerating cases of the quadratic model with $A_{r}=0$, the MCQM has the flexibility to accommodate the EH regression slopes. To illustrate, we also run this forward-rate regression based on the 1,000 paths of simulated forward rates under $(6+1)$ MCQM. Figure 3 plots the medians and $95 \%$ confidence bands of the regression slopes as a function of the forward rate maturity. The median of the regression slopes that are based on the simulated data look close to the sample estimates from the real data. The largest deviation from the null value is at short maturities. The simulation indicates that the sample variation is also the largest at the short maturities.

Our results show that the $(6+1)$ MCQM has the flexibility to accommodate both currency and interest rate forecasting regressions based on various forms of the expectation hypothesis. Nevertheless, the simulation analysis also reveals the large sample variations for these regressions and hence the danger of relying on these regressions to do actual out-of-sample currency and interest rate forecasting.

\section{Conclusion}

In this paper, we propose a multi-currency quadratic model (MCQM) with an $(m+n)$ factor structure. The MCQM can simultaneously model the term structure of interest rates from different countries, as well as the exchange rates between them. The quadratic form enables us to integrate Gaussian state variables, affine market price of risk, and rich nonlinear conditional interest- 
and exchange rate dynamics into one natural framework. While maintaining internal consistency, our $(m+n)$ factor structure explicitly accounts for the fact that a predominant portion of the exchange rate movement is independent of the movements in the term structure of interest rates in either country.

We estimate a series of MCQMs on the panel data of interest rates of both short and long maturities from both the United States and Japan, and the exchange rate between the two countries. Data analysis and the estimation results indicate that the two countries' term structures share moderate comovement, but when we pool the two countries' data, the commonality is not sufficient to generate dimension reduction. Furthermore, we find that the exchange rate between the two currencies moves almost exclusively on its own, independent of the term structure of either country.

Analyzing the estimation results for different $(m+n)$ MCQMs, we find that with $n=1$ the models can capture the ex-post exchange rate movements to near perfection even when the dimension of the interest-rate factors $(m)$ is low. On the other hand, with an $(m+0)$ specification, we need a high dimension on $m$ to generate reasonable performance in exchange rate movements. This finding highlights the crucial role of the additional currency factor in releasing the tensions between interest rate and exchange rate movements that traditional currency pricing models experience.

Comparing different $(m+1)$ models, we find that the $(6+1)$ model statistically dominates all models with fewer interest-rate factors. The dominance shows up not only in the likelihood values, but also in its performance in generating the observed inter- and intra-country interest rate comovements.

Finally, we show that the $(6+1)$ MCQM has the flexibility to accommodate both the currency and the interest rate forecasting regressions that are formulated based on various forms of expectation hypothesis. We also find that the real stylized evidence from these regressions is not that the slope estimate deviates from the null value of one, but that the R-square is always close to zero.

For future research, it would be interesting to link the independent currency risk factor to macroeconomic variables from both economies, such as changes in balance of payments and stock index performances, to achieve a better understanding on the determination of exchange rates. 


\section{Appendix: Unscented Kalman Filter}

The Kalman filter and its various extensions belong to the state space estimation regime and consist of a pair of state propagation equations and measurement equations. In our application, the state vector $Z$ propagates according to the Ornstein-Uhlenbeck process as described in (4) and (5), or its discrete time version in (18),

$$
Z_{t}=\Phi Z_{t-1}+\sqrt{Q} \varepsilon_{t},
$$

which is linear and conditionally normal. For notational clarity, we normalize the time interval to one.

We construct the measurement equation using observations on LIBOR and swap rates from both countries and the depreciation rates of the foreign currency as described in (21). We rewrite this equation in a generic form,

$$
y_{t}=h\left(Z_{t} ; \Theta\right)+e_{t},
$$

where $y_{t}$ denotes the observed series at time $t$ and $h\left(Z_{t} ; \Theta\right)$ denotes their corresponding model values, as a function of the state vector $Z_{t}$ and model parameters $\Theta$. The term $e_{t}$ denotes the measurement error on the series at time $t$. We assume that the measurement error is independent of the state vector and that the measurement error on each series is also mutually independent, but with distinct variance $R_{i i}=\sigma_{i}^{2}, i=1, \cdots, 24 ; R_{i j}=0$ for $i \neq j$.

We use $\bar{Z}_{t}, \bar{V}_{t}, \bar{y}_{t}, \bar{A}_{t}$ denote the time- $(t-1)$ ex ante forecasts of time- $t$ values of the state vector, the covariance of the state vector, the measurement series, and the covariance of the measurement series. We use $\widehat{Z}_{t}$ and $\widehat{V}_{t}$ denote the ex post update, or filtering, on the state vector and its covariance at the time $t$ given observations $\left(y_{t}\right)$ at time $t$. For the linear measurement equation,

$$
y_{t}=H Z_{t}+e_{t},
$$

the Kalman filter provides the most efficient updates. The ex ante predictions are

$$
\begin{aligned}
& \bar{Z}_{t}=\Phi \widehat{Z}_{t-1} ; \\
& \bar{V}_{t}=\Phi \widehat{V}_{t-1} \Phi^{\top}+Q ; \\
& \bar{y}_{t}=H \bar{Z}_{t} ; \\
& \bar{A}_{t}=H \bar{V}_{t} H^{\top}+R,
\end{aligned}
$$

and the ex post filtering updates are, 


$$
\begin{aligned}
\widehat{Z}_{t+1} & =\bar{Z}_{t+1}+K_{t+1}\left(y_{t+1}-\bar{y}_{t+1}\right) ; \\
\widehat{V}_{t+1} & =\bar{V}_{t+1}-K_{t+1} \bar{A}_{t+1} K_{t+1}^{\top},
\end{aligned}
$$

where $K_{t+1}$ is the Kalman gain, given by

$$
K_{t+1}=S_{t+1}\left(\bar{A}_{t+1}\right)^{-1}, \quad S_{t+1}=\bar{V}_{t+1} H .
$$

The iterative procedure defined by (A4) and (A5) gives a time series of the ex ante forecasts and ex post updates on the conditional mean and covariance of the state vectors and the observed series. To estimate model parameters, we define the log-likelihood for each day's observation on the forecasting errors of the observed series,

$$
l_{t+1}(\Theta)=-\frac{1}{2} \log \left|\bar{A}_{t}\right|-\frac{1}{2}\left(\left(y_{t+1}-\bar{y}_{t+1}\right)^{\top}\left(\bar{A}_{t+1}\right)^{-1}\left(y_{t+1}-\bar{y}_{t+1}\right)\right) .
$$

In our application, the measurement equation in (A2) is nonlinear. Traditionally, nonlinearity is often handled by the extended Kalman filter (EKF), which approximates the nonlinear measurement equation with a linear expansion, evaluated at the predicted states

$$
y_{t} \approx H\left(\bar{Z}_{t} ; \Theta\right) Z_{t}+e_{t},
$$

where

$$
H\left(\bar{Z}_{t} ; \Theta\right)=\left.\frac{\partial h\left(\bar{Z}_{t} ; \Theta\right)}{\partial Z_{t}}\right|_{Z_{t}=\bar{Z}_{t}} .
$$

The rest of prediction and updates follow Equations (A4) and (A5). We note that the EKF uses only one point (the conditional mean) from the prior filtering density for the prediction and filtering updates.

In contrast, the unscented Kalman filter (UKF) applied in this paper uses a set of points that are designed to also match higher moments. If we use $p=m+n$ to denote the number of states and use $\delta>0$ as a control parameter, we construct a set of $(2 p+1)$ sigma vectors $\chi_{i}$ according to the following equations:

$$
\begin{aligned}
& \chi_{t, 0}=\widehat{Z}_{t}, \\
& \chi_{t, i}=\widehat{Z}_{t} \pm \sqrt{(p+\delta)\left(\widehat{V}_{t}+Q\right)_{j}}, \quad j=1, \cdots, p ; \quad i=1, \cdots, 2 p,
\end{aligned}
$$


where $A_{i}$ be the $i$ th column of a matrix $A$. The corresponding weights $w_{i}$ are given by

$$
w_{0}=\delta /(p+\delta), \quad w_{i}=1 /[2(p+\delta)], \quad j=1, \cdots, 2 p .
$$

We regard these sigma vectors as forming a discrete distribution with $w_{i}$ as the corresponding probabilities. Then we verify that the mean, covariance, skewness, and kurtosis of this distribution are $\widehat{X}_{t}, \widehat{V}_{t}+Q, 0$, and $p+\delta$, respectively. We use the control parameter $\delta$ to accommodate conditional non-normalities in the state propagation equation.

Given the sigma points, the prediction steps are given by

$$
\begin{aligned}
& \bar{Z}_{t+1}=\sum_{i=0}^{2 p} w_{i}\left(\Phi \chi_{t, i}\right) \\
& \bar{V}_{t+1}=\sum_{i=0}^{2 p} w_{i}\left(\Phi \chi_{t, i}-\bar{X}_{t+1}\right)\left(\Phi \chi_{t, i}-\bar{X}_{t+1}\right)^{\top} ; \\
& \bar{y}_{t+1}=\sum_{i=0}^{2 p} w_{i} h\left(\Phi \chi_{t, i} ; \Theta\right) ; \\
& \bar{A}_{t+1}=\sum_{i=0}^{2 p} w_{i}\left[h\left(\Phi \chi_{t, i} ; \Theta\right)-\bar{y}_{t+1}\right]\left[h\left(\Phi \chi_{t, i} ; \Theta\right)-\bar{y}_{t+1}\right]^{\top}+R,
\end{aligned}
$$

and the filtering updates are given by

$$
\begin{aligned}
& \widehat{Z}_{t+1}=\bar{Z}_{t+1}+K_{t+1}\left(y_{t+1}-\bar{y}_{t+1}\right) ; \\
& \widehat{V}_{t+1}=\bar{V}_{t+1}-K_{t+1} \bar{A}_{t+1} K_{t+1}^{\top},
\end{aligned}
$$

with

$$
\begin{aligned}
K_{t+1} & =S_{t+1}\left(\bar{A}_{t+1}\right)^{-1} \\
S_{t+1} & =\sum_{i=0}^{2 p} w_{i}\left[\Phi \chi_{t, i}-\bar{X}_{t+1}\right]\left[h\left(\Phi \chi_{t, i} ; \Theta\right)-\bar{y}_{t+1}\right]^{\top} .
\end{aligned}
$$

We can modify the above algorithm to handle nonlinearities in the state equation as well as nonadditive errors in the system. For general treatments of the UKF, see Julier (1997). 
To gauge the effectiveness of the UKF and to compare its performance with the traditional EKF, we perform a Monte Carlo simulation exercise. First, from the estimated $(6+1)$ model, we extract the sample path of the state vectors using the UKF. Second, taking the extracted state vector as given, we simulate 1,000 paths of "noisy" exchange rates and interest rates, with the random noise added according to the measurement equations in (21) and the estimated measurement error variance. Third, we run both the UKF and the EKF on the 1,000 sample paths of the simulated noisy observations to extract the state vectors. The effectiveness of each filter is measured by the difference between the values of the original state vector and the corresponding values extracted from the simulated noisy observations. The following table reports the mean absolute difference in percentages of the mean absolute factor value for each of the $(6+1)$ factors.

\begin{tabular}{cccccccc}
\hline Factors & 1 & 2 & 3 & 4 & 5 & 6 & 7 \\
\hline UKF & 1.0708 & 1.4380 & 2.2856 & 1.1753 & 1.0490 & 1.1968 & 9.9989 \\
EKF & 1.0845 & 1.4394 & 2.3308 & 1.1810 & 1.0567 & 1.2401 & 10.0777 \\
\hline
\end{tabular}

The table shows that both filters are effective in extracting the original factors from the noisy observations under our model specification. The absolute differences are about $1-2 \%$ for the interest rate factors and about $10 \%$ for the exchange rate factor. Comparing between the two filters, we find that the absolute differences from the UKF are uniformly smaller from that from the EKF across all factors, showing the added benefit of directly approximating the posterior density in the case of UKF.

\section{References}

Ahn, D.-H., Dittmar, R. F., and Gallant, A. R ((2002)) Quadratic term structure models: Theory and evidence, Review of Financial Studies 15, 243-288.

Ait-Sahalia, Y. ((1996)) Nonparametric pricing of interest rate derivatives, Econometrica 64, 527-560.

Ait-Sahalia, Y. ((1996)) Testing continuous-time models of the spot interest rate, Review of Financial Studies 9, 385-426.

Backus, D., Foresi, S., Mozumdar, A., and Wu, L. ((2001)) Predictable changes in yields and forward rates, Journal of Financial Economics 59, 281-311.

Backus, D., Foresi, S., and Telmer, C. ((2001)) Affine term structure models and the forward premium anomaly, Journal of Finance 56, 279-304.

Bakshi, G. and Naka, A. ((1997)) On the unbiasedness of forward exchange rates, Financial Review 32, 145-162. 
Bansal, R. ((1995)) The dynamics of multiple term structures and exchange rate movements, Working paper, Fuqua School of Business, Duke University.

Bayraktar, Chen, L. and Poor, H. V. ((2005)) Consistency problems with jump-diffusion models, Applied Mathematical Finance 12, 101-119.

Beaglehole, D. R. and Tenney, M. ((1991)) General solution of some interest rate-contingent claim pricing equations, Journal of Fixed Income 1, 69-83.

Beaglehole, D. R., and Tenney, M. ((1992)) A nonlinear equilibrium model of term structures of interest rates: Corrections and additions, Journal of Financial Economics 32, 345-454.

Bekaert, G. ((1995)) The time-variation of expected returns and volatility in foreign exchange markets, Journal of Business and Economic Statistics 13, 397-408.

Bekaert, G., Wei, M., and Xing, Y. ((2003)) Uncovered interest rate parity and the term structure, Working paper, Columbia University.

Benati, L. ((2002)) Affine term structure models for the foreign exchange risk premium, Working paper, Bank of England, Monetary Assessment and Strategy Division.

Brandt, M. and Chapman, D. A. ((2002)) Comparing multifactor models of the term structure, Working paper, Duke University.

Brandt, M. and Santa-Clara, P. ((2002)) Simulated likelihood estimation of diffusions with an application to exchange rate dynamics in incomplete markets, Journal of Financial Economics 63, $161-210$.

Brandt, M. and Yaron, A. ((2001)) Time-consistent no-arbitrage models of the term structure, Working paper, University of Pennsylvania.

Canova, F. and Marrinan, J. ((1995)) Predicting excess returns in financial markets, European Economic Review 39, 35-69.

Chan, K. C., Karolyi, G. A., Longstaff, F. A., and Sanders, A. B. ((1992)) An empirical comparison of alternative models of the short-term interest rate, Journal of Finance 47, 1209-1227.

Cheng, P. and Scaillet, O. ((2002)) Linear-quadratic jump-diffusion modelling with application to stochastic volatility, Working paper, FAME.

Constantinides, G. M. ((1992)) A theory of the nominal term structure of interest rates, Review of Financial Studies 5, 531-552.

Cox, J. C., Ingersoll, J. E., and Ross, S. R. ((1985)) A theory of the term structure of interest rates, Econometrica 53, 385-408.

Dai, Q. and Singleton, K. ((2000)) Specification analysis of affine term structure models, Journal of Finance 55, 1943-1978.

Dai, Q. and Singleton, K. ((2002)) Expectation puzzles, time-varying risk premia, and affine models of the term structure, Journal of Financial Economics 63, 415-441.

Dai, Q. and Singleton, K. ((2003)) Term structure dynamics in theory and reality, Review of Financial Studies 16, 631-678.

Dewachter, H. and Maes, K. ((2001)) An affine model for international bond markets, Working paper, University of Leuven.

Duffee, G. and Stanton, R. ((2005)) EMM and indirect inference estimation of near unit-root processes, Working paper, UC Berkley.

Duffee, G. R. ((1996)) Idiosyncratic variation of Treasury bill yields, Journal of Finance 51, 527-551.

Duffee, G. R. ((2002)) Term premia and interest rate forecasts in affine models, Journal of Finance 57, 405-443.

Duffie, D. ((1992)) Dynamic Asset Pricing Theory, 2nd edn., Princeton University Press Princeton, New Jersey. 
Duffie, D. and Kan, R. ((1996)) A yield-factor model of interest rates, Mathematical Finance 6, 379-406.

Duffie, D. and Singleton, K. ((1997)) An econometric model of the term structure of interest rate swap yields, Journal of Finance 52, 1287-1322.

El Karoui, N., Myneni, R., and Viswanathan, R. ((1992)) Arbitrage pricing and hedging of interest rate claims with state variables: I theory, working paper, University of Paris.

Engel, C. ((1996)) The forward discount anomaly and the risk premium: A survey of recent evidence, Journal of Empirical Finance 3, 123-191.

Fama, E. F. ((1984)) Forward and spot exchange rates, Journal of Monetary Economics 14, 319-338.

Filipović, D. ((1999)) A note on the Nelson-Siegel family, Mathematical Finance 9, 349-359.

Filipović, D. ((2002)) Separable term structures and the maximal degree problems, Mathematical Finance 12, 341-349.

Filipović, D., Chen, L., and Poor, H. V. ((2004)) Quadratic term structure models for risk-free and defaultable rates, Mathematical Finance 14, 515-526.

Fisher, M. and Gilles, C. ((2000)) Modeling the state-price deflator and the term structure of interest rates, Working paper, Federal Reserve Bank of Atlanta/Bear, Stearns \& Co.

Flood, R. and Rose, A. ((1996)) Fixes: Of the forward discount puzzle, Review of Economics and Statistics 78, 748-752.

Flood, R. P. and Taylor, M. P. ((1996)) Exchange rate economics: What is wrong with the conventional approach, in J.A. Frankel, G. Galli, and A. Giovanni (eds.), The Microstructure of Foreign Exchange Markets, University of Chicago Press, Chicago.

Froot, K. A. and Thaler, R. H. ((1990)) Anomalies: Foreign exchange, Journal of Economic Perspectives 4, 179-192.

Gourieroux, C. and Sufana, R. ((2003)) Wishart quadratic term structure models, Working paper, University of Toronto.

Hamilton, J. D. ((1994)) Time Series Analysis, Princeton University Press Princeton, New Jersey.

Han, B. and Hammond, P. ((2003)) Affine models of the joint dynamics of exchange rates and interest rates, Working paper, University of Calgary.

Heidari, M. and Wu, L. ((2003)) Are interest rate derivatives spanned by the term structure of interest rates?, Journal of Fixed Income 13, 75-86.

Hodrick, R. ((1987)) The Empirical Evidence on the Efficiency of Forward and Futures Foreign Exchange Markets, Harwood Academic Publishers, New York.

Hodrick, R. J. and Vassalou, M. ((2002)) Do we need multi-country models to explain exchange rate and interest rate and bond return dynamics?, Journal of Economic Dynamics and Control 26, $1275-1299$.

Inci, A. C. and Lu, B. ((2004)) Exchange rates and interest rates: Can term structure models explain currency movements?, Journal of Economic Dynamics \& Control 28, 1595-1624.

Jamshidian, F. ((1996)) Bond, futures and option valuation in the quadratic interest rate model, Applied Mathematical Finance 3, 93-115.

Julier, S. J. and Uhlmann, J. K. ((1997)) A new extension of the Kalman filter to nonlinear systems, Working paper, University of Oxford Sydney, Australia.

Knez, P. J., Litterman, R., and Scheinkman, J. ((1994)) Explorations into factors explaining money market returns, Journal of Finance 49, 1861-1882.

Leippold, M. and Wu, L. ((2002)) Asset pricing under the quadratic class, Journal of Financial and Quantitative Analysis 37, 271-295. 
Leippold, M. and Wu, L. ((2003)) Design and estimation of quadratic term structure models, European Finance Review 7, 47-73.

Li, H. and Zhao, F. ((2006)) Unspanned stochastic volatility: Evidence from hedging interest rate derivatives, Journal of Finance 61, 341-378.

Litterman, R. and Scheinkman, J. ((1991)) Common factors affecting bond returns, Journal of Fixed Income 1, 54-61.

Longstaff, F. A. ((1989)) A nonlinear general equilibrium model of the term structure of interest rates, Journal of Financial Economics 23, 195-224.

Lothian, J. R. and $\mathrm{Wu}, \mathrm{L}$. ((2002)) Uncovered interest rate parity over the past two centuries, Working paper, Baruch College and Fordham University, New York.

Nielsen, L. T. and Saá-Requejo, J. ((1993)) Exchange rate and term structure dynamics and the pricing of derivative securities, Working paper, INSEAD.

Nowman, K. B. ((1999)) An evaluation of contingent claims using the CKLS interest rate model: An analysis of Australia, Japan, and the United Kingdom, Asia-Pacific Financial Markets 6, 205-219.

Nowman, K. B. ((2001)) Gaussian estimation and forecasting of multi-factor term structure models with an application to Japan and the United Kingdom, Asia-Pacific Financial Markets 8, 23-34.

Phillips, P. C. B. and McFarland, J. W. ((1997)) Exchange rates and interest rates: Further tests of their static and dynamic relationships, Journal of International Money and Finance 16, 885-907.

Roberds, W. and Whiteman, C. ((1999)) Endogenous term premia and anomalies in the term structure of interest rates: Explaining the predictability smile, Journal of Monetary Economics 44, 555-580.

Rogers, L. C. G. ((1997)) The potential approach to the term structure of interest rates and foreign exchange rates, Mathematical Finance 7, 157-176.

Ruge-Murcia, F. J. ((2006)) The expectations hypothesis of the term structure when interest rates are close to zero, Journal of Monetary Economics forthcoming.

Saá-Requejo, J. ((1993)) The dynamics and the term structure of risk premia in foreign exchange markets, Working paper, INSEAD.

Shoji, I. and Ozaki, T. ((1996)) A statistical comparison of the short-term interest rate models for Japan, U.S., and Germany, Asia-Pacific Financial Markets 3, 263-275.

Steeley, J. M. ((1990)) Modeling the dynamics of the term structure of interest rates, The Economic and Social Review 21, 337-361.

Tse, Y. K. ((1995)) Some international evidence on the stochastic behavior of interest rates, Journal of International Money and Finance 14, 721-738.

Vasicek, O. A. ((1977)) An equilibrium characterization of the term structure, Journal of Financial Economics 5, 177-188.

$\mathrm{Wu}$, Y. and Zhang, H. ((1997)) Forward premiums as unbiased predictors of future currency depreciation, Journal of International Money and Finance 16, 609-623. 